\title{
CONCEITOS SOBRE GESTÃO DO CONHECIMENTO: uma revisão sistemática da literatura brasileira
}

\author{
KNOWLEDGE MANAGEMENT CONCEPTS: \\ a systematic review of Brazilian literature
}

Marta Lígia Pomim Valentim ${ }^{1}$

\begin{abstract}
RESUMO
Apresenta-se os conceitos presentes na literatura brasileira sobre gestão do conhecimento e seus elementos constitutivos. A literatura internacional oferece uma quantidade significativa de textos que abordam as concepções, conceitos e definições sobre gestão do conhecimento, contudo, este artigo enfoca apenas a literatura produzida por pesquisadores brasileiros, publicada em periódicos nacionais, no intuito de conhecer o estado da arte sobre gestão do conhecimento e observar a evolução do conceito ao longo do tempo no País. Como procedimentos metodológicos, definiu-se a Revisão Sistemática de Literatura, aplicando-se um protocolo de pesquisa, de maneira a atender o rigor científico para a coleta e a análise dos dados. A partir da análise dos textos recuperados foi possível conhecer os conceitos atribuídos para gestão do conhecimento, bem como os elementos constitutivos mais significativos na visão dos pesquisadores brasileiros.
\end{abstract}

Palavras-chave: Gestão do conhecimento. Conceitos. Compartilhamento de conhecimento. Revisão Sistemática da Literatura. Brasil.

\section{ABSTRACT}

The concepts present in the Brazilian literature on knowledge management and its constitutive elements are presented. The international literature offers a significant amount of texts that address the conceptions, concepts and definitions about knowledge management, however, this article focuses only on the literature produced by Brazilian researchers, published in national journals, in order to know the state of the art on management knowledge and observe the evolution of the concept over time in the country. As methodological procedures, the Systematic Literature Review was defined, applying a research protocol, in order to meet the scientific rigor for the collection and analysis of data. From the analysis of the recovered texts, it was possible to know the concepts attributed to knowledge management, as well as the most significant constitutive elements in the view of Brazilian researchers.

Keywords: Knowledge management. Concepts. Knowledge sharing. Systematic Literature Review. Brazil.

Artigo submetido em 23/09/2020 e aceito para publicação em 18/10/2020

1 Professor Titular. Docente do Programa de Pós-Graduação em Ciência da Informação. Universidade Estadual Paulista Julio de Mesquita Filho. ORCID https://orcid.org/0000-0003-4248-5934. E-mail: valentim@marilia.unesp.br 


\section{INTRODUÇÃo}

Este artigo de revisão apresenta as concepções, conceitos e definições sobre gestão do conhecimento e seus elementos constitutivos mais significativos, de maneira a mais bem compreender como 0 conceito foi evoluindo ao longo do tempo, por meio das investigações realizadas por pesquisadores brasileiros que se dedicaram a conhecer os fenômenos que envolvem a gestão do conhecimento no âmbito da Ciência da Informação.

Os procedimentos metodológicos definidos para atender ao objetivo deste artigo se referem a realização de uma Revisão Sistemática da Literatura (RSL), por meio do estabelecimento de um protocolo de pesquisa (Quadro 1).

Quadro 1 - Protocolo RSL.

\begin{tabular}{|c|c|}
\hline Protocolo RSL & Descrição \\
\hline Objetivo Geral & $\begin{array}{l}\text { Identificar os conceitos sobre gestão do conhecimento e } \\
\text { seus elementos constitutivos mais significativos, publicados } \\
\text { por autores brasileiros no âmbito da Ciência da Informação }\end{array}$ \\
\hline $\begin{array}{l}\text { Fontes de Informação } \\
\text { Pesquisadas }\end{array}$ & $\begin{array}{ll}\text { - } & \text { Base de dados de Periódicos em Ciência da Informação } \\
& \text { (BRAPCI) } \\
\text { - } & \text { Scientific Electronic Library Online (Scielo) } \\
\text { - } & \text { BENANCIB }\end{array}$ \\
\hline Restrição temporal & $\begin{array}{l}\text { - } 0 \text { período pesquisado se refere a: } \\
\text { - BRAPCI - todo o período que consta na base } \\
\text { - SciELO - todo o período que consta na base } \\
\text { - BENANCIB - todo o período que consta na base }\end{array}$ \\
\hline Critérios de Inclusão e de Exclusão & $\begin{array}{l}\text { Inclusão: } \\
\text { - Textos de autores brasileiros } \\
\text { - Textos do campo da Ciência da Informação } \\
\text { Exclusão: } \\
\text { - Textos de autores estrangeiros } \\
\text { - Textos de outras áreas do conhecimento }\end{array}$ \\
\hline Campos Pesquisados & $\begin{array}{l}\text { Campos Pesquisados: } \\
\text { - Título } \\
\text { - Palavras-Chave } \\
\text { - Resumo } \\
\end{array}$ \\
\hline Procedimentos de Seleção & $\begin{array}{l}\text { Procedimento realizado nos textos recuperados: } \\
\text { - Leitura do abstract dos textos recuperados, no intuito de } \\
\text { verificar a pertinência do conteúdo ao objetivo geral deste } \\
\text { Protocolo RSL }\end{array}$ \\
\hline Procedimentos de Análise & $\begin{array}{l}\text { Critérios: } \\
\text { - Identificação de definições e/ou conceitos sobre gestão } \\
\text { do conhecimento e seus elementos constitutivos mais } \\
\text { significativos }\end{array}$ \\
\hline Palavras-Chave Utilizadas & $\begin{array}{l}\text { - Gestão do conhecimento and definição } \\
\text { - Gestão do conhecimento and conceito }\end{array}$ \\
\hline
\end{tabular}

Fonte: Elaboração própria (2020). 
A partir da aplicação do Protocolo RSL (Quadro 1) recuperou-se 49 (quarenta e nove) textos que, após a retirada dos textos duplicados, obteve-se o total de 42 (quarenta de dois) textos para serem avaliados. Deste total, após a leitura do resumo, selecionou-se 20 (vinte) textos para a análise.

Quadro 2 - Produção científica recuperada.

\begin{tabular}{|l|l|c|c|c|c|}
\hline \multicolumn{2}{|l|}{ Fontes de Informação/Palavras-Chave } & BRAPCI & SciELO & BENANCIB & TOTAL \\
\hline \multirow{2}{*}{$\begin{array}{l}\text { Gestão do conheci- } \\
\text { mento and definição }\end{array}$} & Título & 0 & 0 & 1 & $\mathbf{1}$ \\
\cline { 2 - 6 } & Palavra-Chave & 0 & 0 & 0 & $\mathbf{0}$ \\
\cline { 2 - 6 } & Resumo & 9 & 5 & 0 & $\mathbf{1 4}$ \\
\hline \multirow{2}{*}{$\begin{array}{l}\text { Gestão do conheci- } \\
\text { mento and conceito }\end{array}$} & Título & 0 & 0 & 5 & $\mathbf{5}$ \\
\cline { 2 - 6 } & Palavra-Chave & 1 & 0 & 5 & $\mathbf{6}$ \\
\cline { 2 - 6 } & Resumo & 18 & 5 & 0 & $\mathbf{2 3}$ \\
\hline TOTAL & $\mathbf{2 8}$ & $\mathbf{1 0}$ & $\mathbf{1 1}$ & $\mathbf{4 9}$ \\
\hline
\end{tabular}

Fonte: Elaboração própria (2020).

Observa-se que a Base de Dados de Periódicos em Ciência da Informação (BRAPCI) vem se constituindo em uma importante fonte de pesquisa para o campo da Ciência da Informação, em vista da cobertura dada aos periódicos nacionais, recuperando a maior quantidade de textos sobre a temática analisada.

\section{REVISÃO DA LITERATURA BRASILEIRA}

A revisão de literatura é apresentada em ordem cronológica, enfocando as concepções, conceitos e definições sobre gestão do conhecimento e seus elementos constitutivos mais significativos.

Moresi (2001) apresenta os conceitos de Nonaka e Takeuchi (1997) referente a conhecimento tácito e conhecimento explícito, bem como o Processo SECI (socialização, externalização, combinação e internalização); destaca o conceito de conhecimento cultural, a partir dos estudos de Choo (1998), que "[...] consiste das estruturas afetiva e cognitiva que são usadas habitualmente pelos membros de uma organização para perceber, explicar, avaliar e construir a realidade" (MORESI, 2001, p.37); apresenta quatro tipos de conhecimento cultural, a partir dos estudos de Sackmann (1992): conhecimento de dicionário, conhecimento de diretório, conhecimento de manual e conhecimento axiomático. Conceitua gestão do conhecimento como um "[...] conjunto de atividades que busca desenvolver e controlar todo tipo de conhecimento em uma organização, visando à utilização na consecução de seus objetivos" 
(MORESI, 2001, p.37). Apresenta ações básicas para a gestão do conhecimento, quais sejam: descobrir conhecimentos; assegurar que o conhecimento esteja disponível; facilitar o desenvolvimento efetivo de novos conhecimentos; assegurar que os novos conhecimentos sejam disseminados a todos os segmentos da organização; assegurar que o público interno da organização saiba onde estão os conhecimentos e como acessá-los. 0 texto destaca também a aprendizagem organizacional como um elemento importante para este modelo de gestão, a partir dos estudos de Argyris e Schon (1978), Kirn (1996), Kolb (1997) e, nesse contexto, ressalta que a aprendizagem organizacional está interrelacionada as experiências e vivências dos sujeitos organizacionais que, por sua vez, se constitui na base da memória organizacional (STATA, 1997).

Santos e Santana (2002) apresentam o conceito de conhecimento, a partir dos estudos de Dahlberg (1995), Le Coadic (1996), Davenport e Prusak (1999), Drucker (1999), Firestone (1999) e Zack (1999), que o compreendem como um conjunto de informações ao qual um indivíduo the atribui significado e contextualização; destacam a importância de se reconhecer o valor do conhecimento, conforme Houltshouse (1999), inter-relacionando-0 ao capital intelectual da organização; apresentam o termo 'unidade de conhecimento', a partir dos estudos de Rumelhart (1980) e Zack (1999), considerando as inter-relações entre distintas informações significadas e contextualizadas; resgatam os conceitos atribuídos para conhecimento tácito e conhecimento explícito, a partir dos estudos de Polanyi (1966), Nonaka e Takeuchi (1997) e Zack (1999); trazem o conceito de Zack (1999) sobre conhecimento explícito que, pode ser: conhecimento declarativo ou representacional (representação de uma dada realidade vivenciada), conhecimento procedural (como é utilizado e como se opera) e conhecimento causal (sobre por que um fato ocorre). A partir da Teoria Matemática de Comunicação de Shannon e Weaver (1963), explicam que a transmissão no âmbito da gestão do conhecimento, ocorre a partir do valor atribuído ao conjunto de informações inseridas pelo emissor, bem como ao valor atribuído ao conjunto de informações recebidas pelo receptor. Ainda sobre este aspecto, destacam a importância dos repositórios de conhecimento e alertam para os ruídos e perdas que podem ocorrer durante o processo.

Valentim (2002) apresenta os conceitos de dados de Davenport e Prusak (1998) e Miranda (1999); informação por meio dos autores Wurman (1995), Davenport e Prusak (1998), Páez-Urdaneta (1992), Lastres e Albagli (1999), McGarry (1999) e Miranda (1999); e conhecimento a partir das concepções de Davenport e Prusak (1998), Lastres e Albagli (1999), e Miranda (1999). Apresenta o conceito de gestão do conhecimento destacando que seu foco reside no "[...] capital intelectual 
da organização [visando o] desenvolvimento da cultura organizacional voltada ao conhecimento, mapeamento e reconhecimento dos fluxos informais de informação, tratamento, análise e agregação de valor às informações utilizando tecnologias de informação, transferência do conhecimento ou socialização do conhecimento no ambiente organizacional, criação e disponibilização de sistemas de informação empresariais de diferentes naturezas [e] trabalha essencialmente com os fluxos informais" (VALENTIM, 2002, p.4-5). Destaca que há relação entre os termos dados, informação e conhecimento e ressalta que o grau de complexidade muda entre eles, a partir das ações que são realizadas. Ressalta que a gestão da informação atua no âmbito do conhecimento explícito e a gestão conhecimento atua no âmbito do conhecimento tácito.

Brufrem (2004) aborda a ambiguidade conceitual entre os termos 'organização do conhecimento' e 'gestão do conhecimento', relacionada à evolução do campo de atuação profissional e da expansão do modo capitalista das relações sociais e de trabalho. A partir da análise de trabalhos apresentados nos VI Congreso del Capítulo Español de ISKO e IV Coloquio Internacional de Ciencias de la Documentación (2003), realizados na cidade de Salamanca, Espanha, a partir dos subtemas: Fundamentos Epistemológicos e Paradigmas de Investigação em Organização do Conhecimento (14 trabalhos); Tendências de Investigação em Representação do Conhecimento (16 trabalhos); Investigação em Sistemas de Recuperação de Informação e Interfaces de Usuário (12 trabalhos); A Organização do Conhecimento na Gestão do Conhecimento (9 trabalhos); A Organização do Conhecimento no Entorno Digital (14 trabalhos); Metodologias e Técnicas de Investigação em Organização do Conhecimento (4 trabalhos); Comunicação Científica e Difusão da Investigação em Organização do Conhecimento (5 trabalhos); Aspectos Éticos, Sociais e Psicológicos da Investigação em Organização do Conhecimento (2 trabalhos), a pesquisadora conclui que "[...] gestão do conhecimento considerado enquanto ato é sempre uma forma de reconhecimento, ou seja, é produto de interpretações e produz outras representações, podendo ser reprodutora de estruturas e significados que transitam no universo, campo de produção ou de estudos" (BUFREM, 2004, p.8).

Valentim e Gelinski (2005) apresentam o conceito de gestão do conhecimento "[...] como um conjunto de estratégias para criar, adquirir, compartilhar e utilizar ativos de conhecimento, bem como estabelecer fluxos que garantam a informação necessária no tempo e formato adequados, a fim de auxiliar na geração de ideias, solução de problemas e tomada de decisão (VALENTIM; GELINSKI, 2005 apud VALENTIM, 2003, p.1). Resgatam as concepções de Choo (2003) sobre conhecimento tácito, destacando que este é gerado na mente de um sujeito cognoscente, mas ao mesmo tempo demanda 
sua conversão em conhecimento explícito para que possa ser compartilhado aos outros. Mencionam também, a partir dos estudos de Choo (2003), a importância da criação de significado pelos sujeitos organizacionais, por meio da interpretação do contexto vivenciado. Enfatizam a partir dos cinco anéis de Wurman (1995) que a construção de conhecimento faz parte da natureza humana, destacando os níveis que envolvem a geração de conhecimento: informação interna, informação conversacional, informação de referência, informação noticiosa, informação cultural. Apresentam a concepção de Von Krogh, Ichijo e Nonaka (2001) em que mencionam que os processos que envolvem a criação de conhecimento compreendem cinco fases: compartilhamento do conhecimento tácito; criação de conceitos; justificação de conceitos; construção de protótipos; e nivelação do conhecimento. Explicam as diferenças e convergências entre conhecimento tácito e explícito, evidenciando que existe uma dinâmica natural entre ambos, ou seja, que se trata de um processo dialógico. Mencionam que 0 indivíduo necessita desenvolver algumas competências para construir conhecimento: "[...] saber pensar; saber observar; saber estabelecer relações; saber questionar; saber aproveitar o conhecimento acumulado através das experiências vivenciadas ao longo da vida; ter capacidade de apreender; ter consciência da própria ignorância" (VALENTIM; GELINSKI, 2005, p.45). Apresentam alguns conceitos cunhados por Morin (1999) em relação a construção de conhecimento, em que 0 autor evidencia a complexidade da "máquina pensante" destacando o papel da cultura em que o indivíduo está imerso, bem como o papel da linguagem nesse processo. Ressaltam a importância e o papel da cultura organizacional para a gestão do conhecimento, resgatando autores como Terra (2000). Nesse sentido, resgatam o Processo SECI (socialização, externalização, combinação e internalização) de Nonaka e Takeuchi (1997), inter-relacionando-o a existência de uma cultura organizacional favorável para que o referido processo ocorra. Destacam que, além da cultura organizacional como fator determinante para que a gestão do conhecimento efetivamente ocorra, a organização necessita propiciar uma infraestrutura adequada ao desenvolvimento das ações voltadas à gestão do conhecimento. Além das competências anteriormente mencionadas, a partir das concepções de Morin (2002), mencionam algumas atitudes voltadas à construção de conhecimento: 'aprender a aprender', 'aprender a pensar' e ‘aprender a questionar'; voltadas à socialização do conhecimento: 'aprender a compartilhar', 'aprender a compreender' e 'aprender a diversidade intelectual'. Apresentam os conceitos de Maturana e Varela (2001) sobre o processo cognitivo humano para a construção de conhecimento, em que estes autores evidenciam que isso somente é possível porque o sujeito o consolida através da linguagem (signos e símbolos). Resgatam os conceitos de Davenport e Prusak (1998) sobre dados, informação e 
conhecimento, evidenciando a dialogicidade entre os termos. Apresenta a concepção de Carter (2003) em que evidencia a necessidade de o indivíduo realizar atividades cognitivas que, por sua vez, vão ao encontro da gravação do que este se apropriou em termos de dados e informações para que, assim, 0 conhecimento gerado possa ser armazenado tornando-se parte da memória. Apresentam as concepções de Vigotsky (1998) sobre a importância da linguagem para a construção de conhecimento que, segundo 0 autor, se trata de um processo dinâmico do qual a linguagem é essencial. "0 pensamento não é simplesmente expresso em palavras; é por meio delas que ele passa a existir" (VIGOTSKY, 1998, p.156). Explicam, por fim, que a mediação tem um papel importante no contexto da gestão do conhecimento, pois possibilita a apropriação e o compartilhamento de dados, informações e conhecimentos entre os sujeitos organizacionais.

Souto (2007) apresenta as limitações e inconsistências presentes na literatura em relação ao conceito de gestão do conhecimento. Explica que alguns autores como Martensson (2000), Wilson (2002), Kakabadse, Kakabadse e Kouzmin (2003) e Metaxiotis, Ergazakis e Psarras (2005) defendem que o objeto da gestão em si é a informação e não o conhecimento e, portanto, evidenciam a inconsistência do termo 'gestão do conhecimento'. Da mesma maneira, resgata autores como Scarbrough e Swan (2001) que entendiam gestão do conhecimento como um modismo passageiro, ressaltando que as distintas compreensões sobre gestão do conhecimento desgastaram o conceito em si. Objetivando apresentar uma sistematização quanto as limitações e inconsistências em relação ao conceito de gestão do conhecimento, estabeleceu as seguintes categorias de análise: 1) similaridade semântica entre informação e conhecimento, igualando gestão da informação a gestão do conhecimento, destacando nesta categoria os estudos de Dervin (1980; 1989; 1990; 1998, 2001 apud DERVIN; FOREMAN-WERNET; LAUTERBACH, 2003); 2) o objeto/sujeito da gestão, destacando os estudos de Spender (1996), Al-Hawamdeh (2002), Hildreth e Kimble (2002), Schultze e Stabell (2004). Conclui que a gestão do conhecimento pode coordenar "[...] recursos e competências para apoiar um ambiente favorável para o desenvolvimento da aprendizagem e da construção e compartilhamento de significados" (SOUTO, 2007, p.8). A partir das ideias de Hirsch e Levin (1999) e de Grey e Meister (2003), evidencia que o conceito de gestão do conhecimento precisa definir claramente 0 que é e o que não é gestão do conhecimento, pois pode consolidar-se como um "conceito guarda-chuva" ou, ainda, colapsar o conceito. Nesse sentido, entende que a ação humana deve ser inserida no conceito de gestão do conhecimento para que este possa ser compreendido de fato. 
Barbosa (2008) resgata o conceito de Harris (2001) sobre "economia baseada no conhecimento" destacando que autores das áreas de Economia, Finanças e Contabilidade também atribuem significativo grau de importância ao conhecimento no contexto organizacional. Do mesmo modo, apresenta o conceito de comunidades de prática evidenciando os colégios invisíveis como objeto de estudo da gestão do conhecimento. Traz Prusak (2001) que ressalta a geração de ideias inovativas, visando responder a globalização e a competitividade do mercado. Além disso, menciona os sistemas baseados em conhecimento e os sistemas especialistas, relacionados aos campos da Inteligência Artificial e Engenharia do Conhecimento. Apresenta também o conceito de "Ba", cunhado por Nonaka e Konno (1998), relacionado ao ambiente organizacional, que enfoca as condições necessárias ao compartilhamento de conhecimento. Por último, apresenta o conceito de capital intelectual, cunhado por Stewart (1998) que, por sua vez, envolve três elementos: capital humano (talento, experiência e capacidade de inovação), capital estrutural (soma dos ativos tangíveis de uma empresa) e capital do cliente (informações sobre a clientela e o grau de satisfação e de lealdade à organização).

Valentim (2008) conceitua gestão do conhecimento como um "[...] conjunto de atividades que visa trabalhar a cultura organizacional/informacional e a comunicação organizacional/informacional em ambientes organizacionais, no intuito de propiciar um ambiente positivo em relação à criação/ geração, aquisição/apreensão, compartilhamento/socialização e uso/utilização de conhecimento, bem como mapear os fluxos informais (redes) existentes nesses espaços, com o objetivo de formalizálos, na medida do possível, a fim de transformar o conhecimento gerado pelos indivíduos (tácito) em informação (explícito), de modo a subsidiar a geração de ideias, a solução de problemas e o processo decisório em âmbito organizacional (VALENTIM, 2008, p.4). Apresenta as atividades que considera inerentes a gestão do conhecimento: "Identificar necessidades/demandas de conhecimento; Mapear e reconhecer fluxos informais (redes); Desenvolver a cultura organizacional positiva em relação ao compartilhamento/socialização de conhecimento; Proporcionar a comunicação informacional de forma eficiente, utilizando tecnologias de informação e comunicação; Criar espaços criativos dentro da organização; Desenvolver competências e habilidades voltadas ao negócio da organização; Criar mecanismos de captação e sistematização de conhecimento, gerado por diferentes pessoas da organização; Desenvolver e implantar sistemas de diferentes naturezas, visando o compartilhamento e uso de conhecimento; Elaborar e implantar normatizações visando à sistematização do conhecimento gerado internamente; Retroalimentar 0 ciclo" (VALENTIM, 2008, p.4). Ressalta que 0 conceito de gestão do conhecimento não é consenso na área de Ciência da Informação, mas evidencia que 0 
próprio conceito de Ciência da Informação não é consenso no campo científico. Explica que o não consenso advém da compreensão por parte de alguns pesquisadores, como Wilson (2006), por exemplo, de que gestão do conhecimento se refere a gestão da mente humana, o que realmente não é possível. Contudo, explica que a concepção de gestão do conhecimento dos pesquisadores do campo da Ciência da Informação que pesquisam esse fenômeno não é essa. Além disso, evidencia que 0 conceito de gestão do conhecimento varia entre distintos campos científicos como, por exemplo, as áreas de Ciência da Computação, Engenharia da Produção e Administração que, também, estudam gestão do conhecimento, conforme explicam Alvarenga Neto, Barbosa e Pereira (2007). Baseada em autores como Polanyi (1966), Nonaka e Takeuchi (1997), Vigotsky (1998), Morin (1999), Choo (2003) ressalta a dinâmica existente entre informação e conhecimento, cujo processo dual é essencial para a construção de conhecimento. Nessa perspectiva, compreende que a gestão do conhecimento alimenta a gestão da informação que, por sua vez, retroalimenta a gestão do conhecimento, em um ciclo virtuoso. Apresenta a produção científica brasileira sobre gestão da informação e gestão do conhecimento, a partir de periódicos do campo da Ciência da Informação, classificados no estrato 'A' do Qualis Periódicos da Coordenação de Aperfeiçoamento de Pessoal de Nível Superior (CAPES), resgatando 274 artigos. Explica que a produção científica recuperada expressa a importância das linhas de pesquisa dos programas de pós-graduação em Ciência da Informação, pois algumas definem esses fenômenos como interesse de estudo.

Capuano et al. (2009) a partir de uma revisão de literatura apresenta o estado-da-arte conceitual do termo 'inteligência competitiva', evidenciando as conexões epistemológicas com o termo 'gestão do conhecimento'. No que tange a conexão epistemológica destacam autores clássicos como Nonaka e Takeuchi (1997), Daft e Weick (1984), Choo (2003) ressaltando as três arenas: criação de significado, construção do conhecimento e tomada de decisões, e Liebowitz (2006) que inter-relaciona os termos inteligência competitiva, Business Intelligence (BI) e gestão do conhecimento, os integrando no âmbito do termo 'inteligência estratégica'. Os pesquisadores também destacam da obra de Liebowitz (2006) os termos 'capital estrutural' (ativos intangíveis), 'capital de clientela' (stakeholders) e 'capital competitivo' (conhecimento sobre o mercado e concorrentes).

Duarte et al. (2009) analisou trabalhos do Encontro Nacional de Pesquisa e Pós-Graduação em Ciência da Informação (ENANCIB), mais especificamente os apresentados no Grupo de Trabalho 'Gestão da Informação e do Conhecimento (GT-4), no período de 2008 e 2009, considerando 0 "contexto capacitante" da gestão do conhecimento, enfocando dois elementos: as pessoas e a 
tecnologia. Apresentam o conceito de Nonaka e Takeuchi (1997) e de Nonaka e Toyama (2003), que consideram contexto capacitante como um lugar propício a criação de conhecimento, denominado de "Ba". Apresentam conceitos inter-relacionados ao conhecimento e à gestão do conhecimento: Polanyi (1966); Nonaka e Takeuchi (1997); Sveiby (2001); Probst, Raub e Romhardt (2002); Davenport e Prusak (1998); Choo (2003); e Barbosa, Sepúlveda e Costa (2009). Verificaram que na percepção dos apresentadores dos trabalhos no GT-4 do ENANCIB, as pessoas têm papel fundamental no contexto da gestão do conhecimento, pois são geradoras de valor, e constituem o capital intelectual das organizações. Em relação a tecnologia os apresentadores do trabalho entendem que esta se constitui de ferramentas de apoio à gestão do conhecimento e, portanto, essenciais para sua efetividade. Quanto ao contexto capacitante, os autores inferem que a gestão do conhecimento vem se propagando de modo testemunhal, não apenas nos ambientes organizacionais, mas também no âmbito do ENANCIB, cuja característica central e definidora é o capital humano e suas múltiplas interfaces com a Ciência da Informação.

Álvares, Baptista e Araújo Júnior (2010) mencionam que inicialmente Henry (1974) apresentou o termo gestão do conhecimento como sendo políticas públicas voltadas à produção, disseminação, acessibilidade e uso da informação. Destacam que Wiig (1993) definiu gestão do conhecimento como sendo "[...] a construção sistemática, explícita e intencional do conhecimento e sua aplicação para maximizar a eficiência e o retorno sobre os ativos de conhecimento da organização". Apresentam uma categorização conceitual sobre gestão do conhecimento, conforme segue: a) gestão do capital intelectual: lançada por Powell (1993) que a definiu como uma forma integrada e estruturada de gerenciar o capital intelectual de uma organização e, posteriormente, também mencionada por Barclay e Murray (1997), Sullivan (2000), Bukowitz e Williams (2002), e Stewart (2002); b) gestão de ativos intangíveis: a partir do conceito de Sveiby (1998) em que destaca a importância de se atribuir valor ao conhecimento gerado em contextos organizacionais e, posteriormente, também mencionada por Petrash (1996), Hibbard (1997), Davenport e Prusak (1998) e Rowley (1999); c) como processo: ressaltam que a maioria dos textos que apresentam conceitos sobre gestão do conhecimento a entendem como processo e, assim, destacam os seguintes autores: Spek e Spijkervet (1995), Sprenger (1995), Diepstraten (1996), Weggeman (1997), Gurteen (1998), Harris (1999), Van Zolingen, Streumer e Stooker (2001) e Choo (2006); d) como criação de conhecimento organizacional: nessa categoria destacam Nonaka e Takeuchi (1997) ressaltando que estes autores se apoiam nos conceitos de Polanyi (1966), e Marsick e Watkins (1999); e) gestão do intelecto profissional: nesta categoria citam Quinn, Anderson e Finkelstein (2000) 
que, por sua vez, definem quatro aspectos: 1- conhecimento adquirido a partir de treinamento; 2habilidades desenvolvidas a partir de aprendizagem obtida por meio de leituras; 3- conhecimento gerado a partir da rede de relacionamentos; 4- criatividade gerada a partir da vontade, motivação e adaptabilidade; f) a partir dos ativos de informação: destacam o conceito de Allee (1997), Bair e Stear (1997) e Rodrigues (2001) que relacionam o conceito de gestão do conhecimento a algumas atividades informacionais; g) como prática organizacional: sob esta ótica resgatam o conceito da Organization for Economic Co-Operation and Development (OECD) (2002) que enfoca as práticas relativas à geração, captura, disseminação e promoção do compartilhamento do conhecimento; h) por uma perspectiva de aprendizado: destacam Lave e Wenger (1987) e Brown, Collins e Duguid (1989) como precursores do conceito 'aprendizagem situada' relacionada ao conceito de comunidades de prática, destacam Brown e Duguid (2001) que entendem a 'aprendizagem' como o maior desafio da gestão do conhecimento. Finalizam o texto evidenciando que no âmbito da Ciência da Informação existem distintas concepções e compreensões sobre gestão do conhecimento.

Souza, Dias e Nassif (2011) inicialmente explicam que é necessário reconhecer a complexidade inerente a gestão do conhecimento e adotar abordagens teórico-metodológicas integradoras. Apresentam a concepção de Albino e Reinhard (2009) em que destacam a necessidade de haver uma estrutura organizacional para o compartilhamento do capital intelectual; resgatam o conceito de criação de conhecimento de Nonaka e Takeuchi (1997); evidenciam que Barbosa (2008) considera a gestão do conhecimento como um importante fenômeno organizacional, uma vez que está relacionado ao conhecimento pessoal e, por isso, necessita ser compartilhado no contexto organizacional para que possa ser efetivamente utilizado; destacam que Alvarenga Neto, Barbosa e Pereira (2007) mencionam que há uma certa fragilidade terminológica quanto ao termo gestão do conhecimento, entretanto, entendem a complexidade que envolve o termo em si. Nesse sentido, citam Pereira (2002) que ressalta: “[...] neologismos, tais como gestão do conhecimento, gestão empresarial e gestão estratégica do conhecimento, e impropriedades conceituais como o uso da expressão gestão da informação, quando está se referindo à gestão do conhecimento" (SOUZA; DIAS, NASSIF, 2011, p.59). Destacam 0 conceito de Nonaka e Takeuchi (1997) sobre "espiral do conhecimento", conhecida como Processo SECI (socialização, externalização, combinação e internalização), associando-o ao conceito de Brookes (1980), em que explica que a criação de conhecimento a partir da apropriação de uma informação, pode resultar em um novo estado de conhecimento. Resgatam o conceito de Davenport e Prusak (2003) em que esclarecem que um sujeito cria conhecimento a partir das interações entre o conhecimento prévio 
com as novas informações recebidas do ambiente organizacional. Apresentam a compreensão de Awad e Ghaziri (2004) sobre gestão do conhecimento, cujo enfoque recai sobre três fatores básicos: pessoas, tecnologias da informação e processos organizacionais. Ressaltam que Davenport, Marchand e Dickson (2004) mencionaram que, muitas vezes, na literatura o termo gestão do conhecimento é abordado como se fosse gestão da informação, e enfatizam que a gestão do conhecimento abrange questões além da gestão da informação como, por exemplo, relativas à criação e ao uso do conhecimento. Citam Miranda (2004) que entende informação e conhecimento como elementos integrantes do processo de produção e intrínseco ao sujeito organizacional que o realiza. Resgatam a "gestão de pessoas", em que Fischer (2001) explica que este modelo envolve os processos de gestão da informação e do conhecimento, assim, o trabalhador do conhecimento se apresenta como o elemento central do referido modelo. Além disso, inter-relacionam a gestão de pessoas aos processos de aprendizagem, sendo em um primeiro momento individual, e a partir do compartilhamento propiciam a aprendizagem coletiva. Albino e Reinhard (2009) destacam as tecnologias de informação e comunicação como um elemento fundamental para apoiar os processos de gestão do conhecimento. A partir do pensamento de Alvarenga Neto, Barbosa e Pereira (2007), Barbosa (2008), Inazawa (2009), ressaltam a importância da cultura organizacional para a gestão do conhecimento. Paiva, Aragão e Pereira (2005) entendem que a gestão do conhecimento está relacionada aos processos orientados à construção e aplicação de conhecimento no ambiente organizacional. Da mesma maneira, trazem os estudos de Angeloni (2002) que também entende: "[...] uma organização do conhecimento se refere ao conjunto de saberes individuais e coletivos compartilhados pelo grupo é tratado como um ativo valioso, que possibilita a compreensão e a superação das contingências ambientais" (SOUZA; DIAS, NASSIF, 2011, p.63). Destacam também, a partir dos estudos de Sveiby (1998), que os sujeitos organizacionais são os atores responsáveis pela conversão da informação em conhecimento, por meio das próprias competências cognitivas. Resgatam a compreensão de Tiwana (2000) sobre três estágios que envolvem a gestão do conhecimento: aquisição de conhecimento, compartilhamento de conhecimento e utilização de conhecimento. Pereira (2002) menciona algumas práticas voltadas a gestão do conhecimento: aprendizagem organizacional, gestão de competências, gestão do capital intelectual, educação corporativa e inteligência empresarial. Em relação ao compartilhamento do conhecimento como uma ação da gestão do conhecimento, citam os estudos de Albino e Reinhard (2009). Ressaltam a cultura de aprendizagem e o compartilhamento do conhecimento inter-relacionando-os à competência em informação (MIRANDA, 2004) e aos inteligentes coletivos (LÉVY, 2000a; 2000b). Consideram que na perspectiva epistemológica integradora entre a 
gestão da informação e a gestão do conhecimento, a competência informacional e os inteligentes coletivos se inter-relacionam à aprendizagem organizacional e ao compartilhamento de conhecimento.

Bettencourt e Cianconi (2012) apresentam o conceito "espiral do conhecimento", de Nonaka e Takeuchi (1997), destacando o Processo SECI composto pelos processos de socialização, externalização, combinação e internalização. Apresentam também a definição de “comunidades de prática” como “[...] grupos de pessoas com interesses e/ou problemas em comum e que aprofundam seus conhecimentos e competências através da interação com os membros do grupo [...]” (2012, p.12). Evidenciam que a gestão do conhecimento tem origem nos estudos realizados no âmbito da Ciência da Computação, mais especificamente voltados a Inteligência Artificial. As autoras destacam o livro 'Knowledge management foundations: Thinking about thinking - How people and organizations represent, create and use knowledge', de Karl Wiig (1993). E, por fim, evidenciam que "Um dos principais focos da gestão do conhecimento hoje é a colaboração, prevalecendo o estudo de práticas que estimulem 0 compartilhamento e a colaboração para a aprendizagem e produção de conhecimentos” (2012, p.17).

Valentim, Jorge e Ceretta-Soria (2014) analisam as inter-relações entre competência em informação, gestão da informação e gestão do conhecimento. Nesse intuito, apresentam alguns conceitos, definições e modelos dos três objetos de estudo da Ciência da Informação. No que tange especificamente a gestão do conhecimento apresentam o conceito de Lehaney et al. (2004) que evidenciam que a gestão do conhecimento é mais abrangente do simplesmente sistematizar 0 conhecimento gerado por sujeitos organizacionais em sistemas informáticos. Resgatam o conceito de Machado Neto (1998) que explica que a gestão de conhecimento se refere a distintas estratégias que visam gerar, compartilhar e utilizar ativos de conhecimento, visando subsidiar a geração de ideias, a solução de problemas e o processo decisório. Trazem o conceito de Valentim (2008, p.4) sobre gestão do conhecimento como sendo "[...] gestão integrada voltada aos fluxos informais da organização, bem como desenvolve ações direcionadas ao compartilhamento e socialização do conhecimento". Em relação aos modelos de gestão do conhecimento, resgatam as atividades base da gestão do conhecimento de Valentim (2008): a) Identificar necessidades/demandas; b) Mapear e reconhecer fluxos informais; c) Desenvolver a cultura organizacional positiva; d) Proporcionar a comunicação informacional; e) Criar espaços criativos dentro da organização; Desenvolver competências e habilidades; g) Criar mecanismos de captação e sistematização; h) Desenvolver e implantar sistemas de diferentes naturezas; i) Elaborar e implantar normatizações; j) Retroalimentar o ciclo. 0 modelo de Nonaka e Takeuchi (2008) referente ao Processo SECI, composto por: socialização, externalização, combinação. E o modelo de Bukowitz e 
Williams (2002): 1) obtenha; 2) utilize; 3) aprenda; 4) contribua; 5) avalie; 6) construa e mantenha; 7 ) descarte. No intuito de realizarem uma análise comparativa entre competência em informação, gestão da informação e gestão do conhecimento, os autores utilizaram cinco etapas elaboradas por eles, a partir dos estudos da American Library Association (ALA) (1989), Lenox e Walker (1992; 1993), Doyle (1994), Bruce (1997) e Bruce, Edwards e Lupton (2006): 1. Capacidade de reconhecer as necessidades informacionais e formular questões; 2 . Capacidade de identificar, acessar, buscar, pesquisar e localizar a informação em qualquer mídia; 3. Capacidade de organizar, analisar e avaliar a informação; 4. Capacidade de usar eficazmente a informação para uma aplicação prática e solução de problemas; 5 . Capacidade de apropriar-se da informação para gerar novo conhecimento, aprender a aprender. No que tange a gestão da informação utilizaram o modelo de Choo (2003), composto de sete etapas: 1. Necessidades de informação; 2. Aquisição de informação; 3. Organização e armazenamento da informação; 4. Produtos e serviços de informação; 5. Distribuição de informação; 6. Uso de informação; 7. Comportamento adaptativo. Em relação à gestão do conhecimento utilizaram o modelo de Bukowitz e Williams (2002), composto de sete etapas: 1) obtenha; 2) utilize; 3) aprenda; 4) contribua; 5) avalie; 6) construa e mantenha; 7) descarte. A partir da análise comparativa realizada pelos autores, evidenciaram que existem significativas inter-relações entre competência em informação, gestão da informação e gestão do conhecimento.

Hoffmann (2016) apresenta diferenças, semelhanças e interdependências entre os conceitos de gestão do conhecimento, gestão da informação e inteligência competitiva, e propõe um modelo integrado para contextos organizacionais. Destaca o conceito de conhecimento tácito e explícito de Nonaka e Takeuchi (1997); aborda o conceito de capital intelectual, cunhado por Stewart (1998), como sendo a capacidade mental coletiva em um determinado contexto organizacional, bem como menciona os três tipos de capital intelectual: humano, estrutural e de clientes e fornecedores. Destaca o termo denominado de "capital digital" que é conceituado como aquele "[...] consequente do uso da internet que possibilita que as pessoas se contatem, se relacionem, aprendam e compartilhem seu conhecimento" (HOFFMANN, 2016, p.34); apresenta a aprendizagem organizacional como um dos elementos-chave para a efetividade da gestão do conhecimento, apoiada em autores como Senge (1999), Terra (2005), Mishra e Bhaskar (2011); ressalta a importância da gestão por competência no ambiente organizacional, a partir das concepções de Dutra (2004), Amaral (2006) e Carbone et al. (2009), que, por sua vez, integra as competências: organizacional (processos organizacionais, equipamentos e pessoas), essencial (vantagem competitiva) e individual (conhecimento/saber, habilidades/saber fazer e atitudes/saber ser); 
também destaca a gestão da inovação, resgatando os autores Tidd e Bessant (2005), explicando que é um diferencial oriundo de processos de criação, disseminação e compartilhamento de conhecimento; nessa perspectiva traz Davenport e Prusak (1998) que explicam que "[...] criar conhecimento organizacional consiste em gerir pessoas, relações e ambientes organizacionais"; a partir dos autores Lee, Tsai e Amjadi (2012) ressalta que os modelos de gestão do conhecimento devem observar a importância das pessoas nos processos desenvolvidos. Destaca que há vários modelos de gestão do conhecimento presentes na literatura, entre eles: Nonaka e Takeuchi (1995), Davenport e Prusak (1998), Terra (2000), Lee e Kim (2001), Bukowitz e Williams (2002), Probst, Raub e Romhardt (2002), Kakabadse, Kakabadse e Kouzmin (2003), Leite e Costa (2007), Dalkir (2011), Batista (2012), Jannuzzi, Falsarella, Sugahara (2016), entre outros. Apresenta um conceito de gestão do conhecimento: "[...] trata, acima de tudo, de alguns princípios essenciais, como capacitar as pessoas a funcionar em conjunto; preservar sua cultura e valores; garantir aprendizado; criar, descobrir e coletar conhecimentos internos e externos a organização; compartilhar e compreender modelos e as melhores práticas, para que possam ser utilizadas; entre outras" (HOFFMANN, 2016, p.36).

Valentim (2016) apresenta sua compreensão sobre 'conhecimento', destacando que é gerado por um indivíduo, portanto único, pois depende da estrutura cognitiva e vivências do indivíduo que 0 constrói. Resgata o conceito "poder tácito" de Polanyi (1966), destacando que este autor já explicava que a mente humana é o instrumento máximo de nosso conhecimento, tanto teórico quanto prático. Resgata também 0 Processo SECI (socialização, externalização, combinação, internalização) de Nonaka e Takeuchi (1997). Explica que o "[...] conhecimento coletivo e o conhecimento individual em contextos organizacionais são frutos das interações dos sujeitos organizacionais, dos sistemas de informação e da própria estrutura organizacional” (VALENTIM, 2016, p.99). Apresenta o conceito de Valentim e Gelinski (2005) de gestão do conhecimento, já citado anteriormente. Destaca os sete processos da dinâmica do conhecimento propostos por Choo (2003): (i) interpretação da informação; (ii) conversão da informação; (iii) processamento da informação; (iv) criação de significado; (v) construção de conhecimento; (vi) tomada de decisões e (vii) ação organizacional. A partir dos sete processos de Choo (2003), também apresenta sete processos da dinâmica do conhecimento propostos por Valentim (2013): (i) percepção da informação: 0 sujeito organizacional percebe 0 potencial de um dado, reconhecendo-o como uma informação relevante a partir de sua própria competência cognitiva; (ii) ressignificação da informação: 0 sujeito organizacional ressignifica a informação, a partir de suas necessidades informacionais; (iii) contextualização da informação: o sujeito organizacional 
contextualiza a informação, a partir da realidade vivenciada; (iv) apropriação da informação: 0 sujeito organizacional se apropria da informação, a partir de sua compreensão de mundo; (v) construção de 'novo' conhecimento: o sujeito organizacional elabora conhecimento radical ou incremental, a partir das interações com o conhecimento prévio, experiências e vivências anteriores; (vi) tomada de decisão: o sujeito organizacional toma uma decisão, a partir do conhecimento radical ou incremental construído, após avaliar as alternativas mais indicadas para a situação vivenciada; (vii) ação organizacional: 0 sujeito organizacional age, usa, aplica o referido conhecimento no contexto organizacional em que está inserido. Ressalta que Nonaka e Takeuchi (1997) mencionam duas dimensões influenciadoras da construção de conhecimento em contextos organizacionais: a ontológica (conhecimento de mundo construído ao longo da vida) e a epistemológica (conhecimento fundamentado na Ciência construída ao longo da história da humanidade). Resgata os estudos de Nonaka e Konno (1998) no que tange ao compartilhamento e a socialização de conhecimento em ambientes organizacionais que, por sua vez, evidenciam a importância de a organização proporcionar um ambiente favorável para que isso ocorra. Estes autores denominam esse ambiente de "Ba", compreendido como um espaço de compartilhamento dinâmico que possibilita a criatividade, o desenvolvimento, a transformação, a partir das interações entre os sujeitos organizacionais. Apresenta alguns aspectos voltados à criação de conhecimento, a partir da concepção de Malhotra (2000): imaginação; criatividade; percepção do próprio conhecimento; reconhecimento do conhecimento relevante para um dado contexto; agregação de valor ao conhecimento existente. Ressalta também a importância da cultura organizacional para a gestão do conhecimento, pois argumenta que dependendo dos valores culturais e comunicacionais dos sujeitos organizacionais, o compartilhamento e a socialização de conhecimento não ocorrerá. Nesse sentido, apresenta alguns fatores considerados por Oye, Mazleena e Noorminshah (2011) como determinantes para o compartilhamento de conhecimento: segurança no trabalho; empregabilidade por meio de capacitação; gestão transparente da alta administração; equidade quanto a aplicação das normas organizacionais; apoio/suporte organizacional para o desenvolvimento de atividades/ tarefas; recompensa pelo trabalho realizado. Menciona que a gestão do conhecimento pode contribuir enormemente para que esses fatores sejam implementados nas organizações. A partir dos estudos de distintos autores, apresenta e descreve sobre alguns métodos e técnicas de compartilhamento de conhecimento que podem ser aplicados no contexto organizacional: brainstorm (BESANT, 2016); redes colaborativas (VALENTIM, 2013); benchmarking (PEMBERTON; STONEHOUSE; YARROW, 2001); storytelling (MATOS, 2010; (TERRA, s.d.); páginas amarelas (VALENTIM, 2013; AHMED; 2016); 
mapas de conhecimento (NURCAN; BARRIOS, 2003; NOVAK, 2009); programas de competência em informação (VALENTIM, 2013). Apresenta a concepção de Hegazy e Ghorab (2014) que ressaltam que o compartilhamento e a socialização geram seis níveis de impacto organizacionais: eficiência; eficácia; inovação; adaptabilidade; aprendizagem; satisfação. Nessa perspectiva, resgata os estudos de BecerraFernandez e Sabherwal (2010) que evidenciaram o impacto do compartilhamento e socialização do conhecimento em quatro elementos organizacionais: pessoas; processos; produtos; desempenho organizacional. Destaca os estudos de Nemati (2015) que evidencia que o compartilhamento de conhecimento influi diretamente na sociabilidade organizacional e, assim, melhora as condições de adaptabilidade. Destaca os estudos de Bradshaw, Chebbi e Oztel (2015) que ressaltam o papel dos líderes nesses processos de compartilhamento e socialização do conhecimento. Apresenta os seis elementos influenciadores para o compartilhamento e a socialização de conhecimento no entendimento de Albers (2009): cultura, liderança, processos de conhecimento, estrutura organizacional, infraestrutura de tecnologia e missão organizacional. Do mesmo modo, resgata a compreensão de Ardichvili et al. (2006) que evidenciam elementos positivos e negativos ao compartilhamento em contextos organizacionais, portanto, complexos sob o ponto de vista da gestão do conhecimento.

Correa (2019) apresenta um delineamento teórico conceitual sobre o que denominou de gestão do conhecimento holística. Para tanto, se apoia na teoria paradigmática de Kuhn (1975) destacando primeiramente o paradigma cartesiano-newtoniano e, posteriormente, o paradigma holístico, de modo a subsidiar uma melhor compreensão sobre a gestão do conhecimento holística. Apresenta o termo 'holístico' originário do Grego 'hólus' e que está relacionado ao todo, inteiro, completo e integro. Em relação ao paradigma holístico, apresenta o conceito de Weil (1991) que o compreende como o reestabelecimento da unidade totalitária, fragmentada pelo reducionismo no contexto do paradigma cartesiano. Destaca alguns estudos realizados que indicam a necessidade de os estudos da gestão do conhecimento serem inter, pluri/multi e/ou transdisciplinares (SCHOLL et al., 2004; MORIN, 2005; BEGOÑA LLORIA, 2008; HEISIG, 2009). Após descrever e explicar os paradigmas supracitados, evidencia que o campo de estudo sobre gestão do conhecimento se constituiu no paradigma cartesianonewtoniano (BOLISANI; HANDZIC, 2015), entretanto, como trata de questões complexas necessita que os estudos desenvolvidos neste âmbito se baseiem no paradigma holístico. Nesse intuito, evidencia que os modelos de gestão do conhecimento, em geral, contemplam aspectos distintos em suas estruturas, abrangendo o todo e não somente uma parte do fenômeno. Apresenta o pensamento de Cajueiro (2008) que considera os modelos teórico-conceituais de gestão do conhecimento como sendo a sistematização 
de uma determinada realidade, visando demonstrar relacionamentos complexos. No entanto, ressalta que tais modelos são reducionistas e, assim, evidencia que há a necessidade de uma abordagem holística para a gestão do conhecimento. Para comprovar esta afirmativa apresenta os achados, a partir da análise de diferentes modelos de gestão do conhecimento realizadas por: Holsapple e Joshi (1999) (10 modelos); Rubenstein-Montano et al. (2001) (26 modelos); Heisig (2009) (160 modelos); Fteimi (2015) (74 modelos), totalizando 270 modelos analisados. Conceitua gestão do conhecimento holística como "[...] uma proposta que visa abordar as partes pelo todo, considerando que essas partes não devem ser analisadas de forma isolada por haver uma interligação entre essas e, portanto, resulta em recontextualizar essas partes num molde que contemple a totalidade" (CORREA, 2019, p.142).

Sampaio e Menezes (2019) destacam, conforme menciona Longo et al. (2014), que na Década de 1990, a gestão do conhecimento se consolida como recurso estratégico; explicam, a partir de Carvalho (2012), que o conhecimento é dependente de processos subjetivos e complexos; trazem o conceito de gestão do conhecimento de Davenport e Prusak (2003, p.53): "[...] criar um conjunto de funções e qualificações para desempenhar o trabalho de apreender, distribuir e usar o conhecimento"; outro conceito de gestão do conhecimento apresentado se refere ao de Seaton-Moore e Bresó-Bolinches (2001) que a considera como um conjunto de processos de aprendizagem e desenvolvimento organizacional com potencial para a geração de recursos econômicos; traz Ribeiro e Chassagnes-Izquierdo (2017) que explicam dois diferentes enfoques para a gestão do conhecimento, sendo o primeiro enfoque relacionado a compreensão de que o conhecimento é um recurso estratégico para as organizações, e 0 segundo enfoque que compreende o conhecimento como um ativo para criar e reter valor; resgatam os estudos de Takeuchi e Nonaka (2008) em que estes destacam os processos de criação e disseminação do conhecimento, inter-relacionando-os aos fluxos informacionais das organizações. Mencionam que Takeuchi e Nonaka se baseiam nos estudos de Polanyi (1967) no que tange aos conceitos de tácito e explícito, destacando o movimento dialético existente entre eles. Explicam, a partir dos estudos de Peluffo-Argón e Catalán-Contreras (2002) e de Ribeiro e Chassagnes-Izquierdo (2017), que as metas da gestão do conhecimento são: meios para a obtenção de informação e conhecimento, aprendizagem organizacional, criar uma base de conhecimento, a partir das experiências e vivências visando gerar diferenciais estratégicos para a organização. Esclarecem que as definições encontradas sobre gestão do conhecimento evidenciam uma dinâmica que integra a apropriação de informações, a formação de um repertório cognitivo e a geração de interpretações, visando a solução de problemas organizacionais. Destacam, a partir dos estudos de Leite (2007), que a comunicação entre os sujeitos organizacionais 
possibilita a criação e o compartilhamento de conhecimento de maneira efetiva. Do mesmo modo, destacam que a cultura também se constitui em um elemento influenciador importante para a gestão do conhecimento.

Álvares et al. (2020) explicam que o conceito de conhecimento tácito está inter-relacionado aos paradigmas humanista e organizacional, o primeiro alinhado aos estudos das Artes, Antropologia, Filosofia, Geografia, História, Pedagogia e Psicologia; 0 segundo vinculado às disciplinas de Administração, Comunicação, Contabilidade, Economia e Marketing. Por outro lado, o conceito de conhecimento explícito está inter-relacionado aos paradigmas tecnológico e sociotécnico, sendo 0 primeiro relacionado às disciplinas da Ciência da Computação, Engenharia de Redes, Sistemas de Informação e Segurança de Informação; e o segundo aderente às disciplinas Ciência da Informação, Estatística, Linguística e Sociologia. Ressaltam que os conceitos consolidados e inter-relacionados a gestão do conhecimento são: o conhecimento tácito (paradigma humanista ) e explícito (paradigma tecnológico); a informação estruturada (paradigma sociotécnico) e não estruturada (paradigma organizacional); e características relativas a objetividade e subjetividade.

Barbosa (2020) destaca que o conceito de "Ba", cunhado por Nonaka e Takeuchi (1995), se refere a um contexto compartilhado para a criação de conhecimento. A partir dos mesmos autores supracitados apresenta também o Processo SECI, composto por quatro processos básicos: socialização; externalização; combinação; internalização. Destaca a aplicação de modelos de gestão de conhecimento em distintas áreas do conhecimento. Por último, destaca que há uma variedade de aplicações para a gestão do conhecimento, e enfatiza a necessidade de se desenvolver estudos inter-relacionando a gestão do conhecimento com temas emergentes como a robótica, a inteligência artificial e 0 big data.

\section{CONSIDERAÇÕES FINAIS}

A gestão do conhecimento se alicerça em uma gama de disciplinas. Como aprendemos e construímos conhecimento, visando o compartilhamento e a socialização se constituem no enfoque da gestão do conhecimento. Além disso, vale ressaltar as tecnologias que podem ser aplicadas no intuito de contribuir para a gestão do conhecimento como, por exemplo, os sistemas especialistas, a inteligência artificial, sistemas de apoio à decisão, big data analytics, redes semânticas, bancos e bases de conhecimento, entre outros recursos. 
A partir da análise dos artigos selecionados verificou-se que os pesquisadores brasileiros se baseiam e se utilizam de conceitos de autores consagrados internacionalmente, entre eles pode-se destacar: Nonaka e Takeuchi (em 19 textos dos 20 analisados); Davenport e Prusak (em 11 textos dos 20 analisados); Choo (em 10 textos dos 20 analisados); Polanyi (em 6 textos dos 20 analisados). Alguns pesquisadores brasileiros atribuíram conceitos à gestão do conhecimento, contribuindo para o estado da arte do campo da Ciência da Informação (Quadro 3):

Quadro 3 - Conceitos de pesquisadores brasileiros sobre gestão do conhecimento.

\begin{tabular}{|c|c|}
\hline & Conceitos de Gestão do Conhecimento \\
\hline $\begin{array}{l}\text { Moresi } \\
(2001, \text { p.37) }\end{array}$ & $\begin{array}{l}\text { "[...] conjunto de atividades que busca desenvolver e controlar todo tipo de conhecimento em uma organização, } \\
\text { visando à utilização na consecução de seus objetivos". }\end{array}$ \\
\hline $\begin{array}{l}\text { Valentim } \\
(2002, \text { p.4-5) }\end{array}$ & $\begin{array}{l}\text { "[...] capital intelectual da organização [visando o] desenvolvimento da cultura organizacional voltada ao } \\
\text { conhecimento, mapeamento e reconhecimento dos fluxos informais de informação, tratamento, análise e } \\
\text { agregação de valor às informações utilizando tecnologias de informação, transferência do conhecimento } \\
\text { ou socialização do conhecimento no ambiente organizacional, criação e disponibilização de sistemas de } \\
\text { informação empresariais de diferentes naturezas [e] trabalha essencialmente com os fluxos informais" }\end{array}$ \\
\hline Brufrem & $\begin{array}{l}\text { "[...] gestão do conhecimento considerado enquanto ato é sempre uma forma de reconhecimento, ou seja, } \\
\text { é produto de interpretações e produz outras representações, podendo ser reprodutora de estruturas e } \\
\text { significados que transitam no universo, campo de produção ou de estudos". }\end{array}$ \\
\hline $\begin{array}{l}\text { Valentim e Gelinski } \\
\text { (2005) }\end{array}$ & $\begin{array}{l}\text { "[...] como um conjunto de estratégias para criar, adquirir, compartilhar e utilizar ativos de conhecimento, } \\
\text { bem como estabelecer fluxos que garantam a informação necessária no tempo e formato adequados, a fim de } \\
\text { auxiliar na geração de ideias, solução de problemas e tomada de decisão" (VALENTIM; GELINSKI, } 2005 \text { apud } \\
\text { VALENTIM, 2003, p.1). }\end{array}$ \\
\hline Valentim & $\begin{array}{l}\text { "[...] conjunto de atividades que visa trabalhar a cultura organizacional/informacional e a comunicação } \\
\text { organizacional/informacional em ambientes organizacionais, no intuito de propiciar um ambiente positivo } \\
\text { em relação à criação/geração, aquisição/apreensão, compartilhamento/socialização e uso/utilização de } \\
\text { conhecimento, bem como mapear os fluxos informais (redes) existentes nesses espaços, com o objetivo de } \\
\text { formalizá-los, na medida do possível, a fim de transformar o conhecimento gerado pelos indivíduos (tácito) } \\
\text { em informação (explícito), de modo a subsidiar a geração de ideias, a solução de problemas e o processo } \\
\text { decisório em âmbito organizacional”. }\end{array}$ \\
\hline $\begin{array}{l}\text { Álvares, B } \\
\text { Araújo Jú }\end{array}$ & $\begin{array}{l}\text { Apresentam uma categorização conceitual sobre gestão do conhecimento [...]: gestão do capital intelectual } \\
\text { [...]; gestão de ativos intangíveis [...]; como processo [...]; como criação de conhecimento organizacional [...]; } \\
\text { gestão do intelecto profissional[...]; a partir dos ativos de informação [...]; como prática organizacional [...]; } \\
\text { por uma perspectiva de aprendizado [...]. }\end{array}$ \\
\hline $\begin{array}{l}\text { Souza, Dias e Nassif } \\
\text { (2011) }\end{array}$ & $\begin{array}{l}\text { Consideram que na perspectiva epistemológica integradora entre a gestão da informação e a gestão do } \\
\text { conhecimento, a competência informacional e os inteligentes coletivos se inter-relacionam à aprendizagem } \\
\text { organizacional e ao compartilhamento de conhecimento. }\end{array}$ \\
\hline $\begin{array}{l}\text { Bettencourt e } \\
\text { Cianconi } \\
(2012, \text { p.17) }\end{array}$ & $\begin{array}{l}\text { "Um dos principais focos da gestão do conhecimento hoje é a colaboração, prevalecendo o estudo de práticas } \\
\text { que estimulem o compartilhamento e a colaboração para a aprendizagem e produção de conhecimentos". }\end{array}$ \\
\hline Hoffmann (2016) & $\begin{array}{l}\text { "[...] trata, acima de tudo, de alguns princípios essenciais, como capacitar as pessoas a funcionar em conjunto; } \\
\text { preservar sua cultura e valores; garantir aprendizado; criar, descobrir e coletar conhecimentos internos e } \\
\text { externos a organização; compartilhar e compreender modelos e as melhores práticas, para que possam ser } \\
\text { utilizadas; entre outras" }\end{array}$ \\
\hline $\begin{array}{l}\text { Correa } \\
(2019, \text { p.142) }\end{array}$ & $\begin{array}{l}\text { Conceitua "[...] gestão do conhecimento holística como uma proposta que visa abordar as partes pelo todo, } \\
\text { considerando que essas partes não devem ser analisadas de forma isolada por haver uma interligação entre } \\
\text { essas e, portanto, resulta em recontextualizar essas partes num molde que contemple a totalidade". }\end{array}$ \\
\hline
\end{tabular}

Fonte: Elaboração própria a partir dos dados coletados na pesquisa (2020). 
Vale ressaltar os elementos constitutivos da gestão do conhecimento, a partir da compreensão dos autores dos textos analisados. A aprendizagem organizacional é um elemento recorrente no âmbito da gestão do conhecimento na literatura brasileira, pois os pesquisadores a compreendem como inerente aos contextos das comunidades de prática e das redes formais e informais existentes no ambiente organizacional, bem como a inter-relacionam à competência em informação e à construção de conhecimento que, por sua vez, podem propiciar criatividade e inovação, evidenciando que a gestão do conhecimento necessariamente deve proporcionar as condições necessárias para que a aprendizagem possa ocorrer.

Outro elemento recorrente nos textos analisados se refere ao compartilhamento e socialização do conhecimento, visto que são elementos basilares para a gestão do conhecimento, ou seja, proporcionar as condições necessárias em termos de infraestrutura, tecnologias e processos, bem como desenvolver as competências essenciais nos sujeitos organizacionais, de modo que possuam habilidades e atitudes voltadas ao compartilhamento e a socialização de dados, informações e conhecimentos.

A cultura organizacional e a cultura informacional, também, se constituem em elementos significativos para a gestão do conhecimento, uma vez que alguns pesquisadores evidenciaram que sem uma cultura positiva e voltada a aprendizagem e ao compartilhamento de dados, informação e conhecimento, dificilmente a gestão do conhecimento terá êxito nos ambientes organizacionais.

Outros elementos como a comunicação organizacional, a competência em informação, a apropriação de dados e informações para a construção de conhecimento, a mediação de dados, informações e conhecimentos, as tecnologias de informação e comunicação também aparecem nos textos analisados.

A partir da análise da literatura brasileira oriunda de pesquisadores brasileiros foi possível conhecer o estado da arte da gestão do conhecimento, por meio das concepções, conceitos e definições atribuídos. Acredita-se que é um conceito consolidado que expressa similaridade e convergência, evidenciando consistência terminológica e conceitual.

\section{REFERÊNCIAS}

AHMED, H. K. The role of knowledge management in developing the talents performance in organizations. International Journal of Management and Applied Science, v.2, n.12, Special Issue-1, Dec. 2016. Disponível em: http://www.iraj.in/journal/journal_file/journal_pdf/14-328-14855740188995.pdf Acesso em: 10 set. 2020. 
ALA - AMERICAN LIBRARY ASSOCIATION. Presidential Committee on Information Literacy: Final Report. Chicago: ALA, 1989. Disponível em: http://www.ala.org/acrl/publications/whitepapers/ presidential Acesso em: 10 set. 2020.

ALBERS, J. A. A practical approach to implementing knowledge management. Journal of Knowledge Management Practice, v.10, n.1, Mar. 2009. Disponível em: http://www.tlainc.com/articl174.htm Acesso em: 10 set. 2020.

ALBINO, J. P.; REINHARD, N. Kmauditbr: uma ferramenta para diagnóstico e avaliação de sistemas de gestão de conhecimento. Revista Gestão Industrial, Ponta Grossa (PR), v.5, n.2, p.61-79, 2009. Disponível em: https://periodicos.utfpr.edu.br/revistagi/article/view/345/286 Acesso em: 10 set. 2020.

AL-HAWAMDEH, S. Knowledge management: Re-thinking information management and facing the challenge of managing tacit knowledge. Information Research, v.8, n.1, Oct. 2002. Disponível em: http://informationr.net/ir/8-1/paper143.html Acesso em: 10 set. 2020.

ALLEE, V. The Knowledge evolution: Expanding organizational intelligence. Boston: ButterworthHeinemann, 1997. 296p.

ALVARENGA NETO, R. C. D.; BARBOSA, R. R.; PEREIRA, H. J. Gestão do conhecimento ou gestão de organizações da era do conhecimento? Um ensaio teórico-prático a partir de intervenções na realidade brasileira. Perspectivas em Ciência da Informação, Belo Horizonte, v.12, n.1, p.5-24, jan./ abr. 2007. Disponível em: https://doi.org/10.1590/S1413-99362007000100002 Acesso em: 10 set. 2020.

ÁLVARES, L. M. A. R.; BAPTISTA, S. G.; ARAÚJO JÚNIOR, R. H. A. Gestão do conhecimento: categorização conceitual. Em Questão, Porto Alegre, v.16, n.2, p.235-252, jul./dez. 2010. Disponível em: https://seer.ufrgs.br/EmQuestao/article/view/15124/10437 Acesso em: 10 set. 2020.

ÁLVARES, L. M. A. R.; SOARES, C. M. L. C.; MACHADO, N. J. P.; VIANNA, E. W.; SILVA, T. F.; ARAGÃO, J.; GREENHALGH, M. Interfaces disciplinares selecionadas da gestão do conhecimento: características, contribuições e reflexões. Em Questão, Porto Alegre, v.26, n.2, p.132-160, maio/ago. 2020. Disponível em: https://seer.ufrgs.br/EmQuestao/article/view/94524/56604 Acesso em: 10 set. 2020.

AMARAL, R. M. Desenvolvimento e aplicação de um método para o mapeamento de competências em inteligência competitiva. 2006. 209f. Dissertação (Mestrado) - Programa de Pós-Graduação em Engenharia de Produção, Universidade Federal de São Carlos (UFSCar), São Carlos, 2006. Disponível em: https://repositorio.ufscar.br/bitstream/handle/ufscar/3807/832.pdf?sequence=1\&isAllowed=y Acesso em: 10 set. 2020.

ANGELONI, M. T. (Org.). Organizações do conhecimento: infraestrutura, pessoas e tecnologias. São Paulo: Saraiva, 2002. 115p.

ARDICHVILI, A. et al. Cultural influences on knowledge sharing through online communities of practice. Journal of Knowledge Management, v.10, n.1, p.94-107, 2006. Disponível em: https://doi. org/10.1108/13673270610650139 Acesso em: 10 set. 2020. 
ARGYRIS, C.; SCHON, D. Organizational learning: A theory of action perspective. Reading (MA): Addison-Wesley, 1978. 356p.

AWAD, E. M., GHAZIRI, H. M. Knowledge management. New Jersey: Prentice-Hall, 2004. 480p.

BAIR, J.; STEAR, E. Information management is not knowledge management. Stamford (CT): Gartner Group Research Note, 1997.

BARBOSA, R. R. Gestão da informaç̧ão e gestão do conhecimento: evolução e conexões.

Perspectivas em Ciência da Informação, Belo Horizonte, v.25, n. esp., p.168-186, fev. 2020. Disponível em: http://portaldeperiodicos.eci.ufmg.br/index.php/pci/article/view/4303/2354 Acesso em: 10 set. 2020.

BARBOSA, R. R. Gestão da informação e do conhecimento: origens, polêmicas e perspectivas. Informação \& Informação, Londrina (PR), v.13, n. esp., p.1-25, 2008. Disponível em: http://www.uel. br/revistas/uel/index.php/informacao/article/view/1843/1556 Acesso em: 10 set. 2020.

BARCLAY, R. 0.; MURRAY, P. C. What is knowledge management? Knowledge Praxis, 1997. Disponível em: http://providersedge.com/docs/km_articles/What_Is_Knowledge_Management.pdf Acesso em: 10 set. 2020.

BATISTA, F. F. Modelo de gestão do conhecimento para a administração pública brasileira: como implementar a gestão do conhecimento para produzir resultados em benefício do cidadão. Brasília: IPEA, 2012. 132p. Disponível em: https://www.ipea.gov.br/portal/images/stories/PDFs/livros/livros/ livro_modelodegestao_vol01.pdf Acesso em: 10 set. 2020.

BECERRA-FERNANDEZ, I.; SABHERWAL, R. Knowledge management: Systems and processes. Manachira, Calicut (India): TBS Books, 2010.

BEGOÑA LLORIA, M. A review of the main approaches to knowledge management. Knowledge Management Research \& Practice, v.6, n.1, p.77-89, 2008. Disponível em: https://doi.org/10.1057/ palgrave.kmrp. 8500164 Acesso em: 10 set. 2020.

BESANT, H. The journey of brainstorming. Journal of Transformational Innovation, v.2, n.1, p.1-7, Summer. 2016. Disponível em: http://www.regent.edu/acad/global/publications/jti/vol2iss1/Besant_ JTISU16A.pdf Acesso em: 10 set. 2020.

BETTENCOURT, M. P. da L.; CIANCONI, R. de B. Gestão do conhecimento: um olhar sob a perspectiva da ciência da informação. In: ENCONTRO NACIONAL DE PESQUISA EM CIÊNCIA DA INFORMAÇÃO, 13., 2012, Rio de Janeiro. Anais Eletrônico... Rio de Janeiro: FIOCRUZ; ANCIB, 2012. Disponível em: http://enancib.ibict.br/index.php/enancib/xiiienancib/paper/viewFile/3746/2869 Acesso em: 10 set. 2020.

BOLISANI, E.; HANDZIC, M. (Eds.). Advances in knowledge management: Celebrating twenty years of research and practice. New York: Springer, 2015. 219p.

BRADSHAW, R.; CHEBBI, M.; ÖZTEL, H. Leadership and knowledge sharing. Asian Journal of Business Research, Special Issue, p.1-20, 2015. Disponível em: DOI https:// 
www.semanticscholar.org/paper/Leadership-and-Knowledge-Sharing-Bradshaw-Chebbi/ f4ff44a040fc64efb1de223f5902bbe4248340ef Acesso em: 10 set. 2020.

BR00KES, B. C. The foundations of Information Science: Part I - Philosophical aspects. Journal of Information Science, v.2, n.3-4, p.125-133, Jun. 1980. Disponível em: https://doi. org/10.1177/016555158000200302 Acesso em: 10 set. 2020.

BROOKES, B. C. The foundations of information science: Part II - Quantitative aspects: classes of things and the challenge of human individuality. Journal of Information Science, v.2, n.5, p.209-221, Oct. 1980. Disponível em: https://doi.org/10.1177/016555158000200502 Acesso em: 10 set. 2020.

BR00KES, B. C. The foundations of information science: Part III - Quantitative aspects: objective maps and subjective landscapes. Journal of Information Science, v.2, n.6, p.269-275, Dec. 1980. Disponível em: https://doi.org/10.1177/016555158000200602 Acesso em: 10 set. 2020.

BROWN, J. S.; COLLINS, A.; DUGUID, P. Situated learning and the culture of learning. Educational Researcher, Washington, v.18, n.1, p.32-42, Jan. 1989. Disponível em: https://doi. org/10.3102/0013189X018001032 Acesso em: 10 set. 2020.

BROWN, J. S.; DUGUID, P. A vida social da informação. São Paulo: Makron Books, 2001.

BRUCE, C. S. Seven faces of information literacy in higher education. Adelaide: Auslib Press, 1997. $203 p$.

BRUCE, C.; EDWARDS, S.; LUPTON, M. Six frames for information literacy education: A conceptual framework for interpreting the relationships between theory and practice. Innovation in Teaching and Learning in Information and Computer Sciences, v.5, n.1, p.1-18, Jan. 2006. Disponível em: https:// doi.org/10.11120/ital.2006.05010002 Acesso em: 10 set. 2020.

BUFREM, L. S. Levantando significações para significantes: da gestão do conhecimento a organização do saber. Encontros Bibli: Revista Eletrônica de Biblioteconomia e Ciência da Informação, Florianópolis, n. esp., p.1-10, 1. sem., 2004. Disponível em: https://periodicos.ufsc.br/index.php/eb/ article/view/1518-2924.2004v9nesp1p1/5277 Acesso em: 10 set. 2020.

BUKOWITZ, W.; WILLIAMS, R. L. Manual de gestão do conhecimento: ferramentas e técnicas que criam valor para empresa. Porto Alegre: Bookman, 2002. 399p.

CAJUEIRO, J. L. G. Modelo de gestão do conhecimento para instituições de ensino superior. 2008. 152f. Tese (Doutorado) - Programa de Pós-Graduação em Engenharia de Produção, Universidade Federal de Pernambuco (UFPE), 2008. Disponível em: https://repositorio.ufpe.br/ bitstream/123456789/4985/1/arquiv03735_1.pdf Acesso em: 10 set. 2020.

CAPUANO, E. A.; CASAES, J. C. C.; COSTA, J. R.; JESUS, M. S. de; MACHADO, M. A. Inteligência competitiva e suas conexões epistemológicas com gestão da informação e do conhecimento. Ciência da Informação, Brasília, v.38, n.2, p.19-34, ago. 2009. Disponível em: http://revista.ibict.br/ciinf/ article/view/1242/1420 Acesso em: 10 set. 2020. 
CARBONE, P. P. et al. Gestão por competências e gestão do conhecimento. 3.ed. Rio de Janeiro: Editora FGV, 2009. 176p.

CARTER, R. 0 livro de ouro da mente: o funcionamento e os mistérios do cérebro humano. Rio de Janeiro: Ediouro, 2003. 431p.

$\mathrm{CHOO}, \mathrm{C} . \mathrm{W}$. The knowing organization: How organizations use information to construct meaning, create knowledge and make decisions. 2.ed. New York: Oxford University Press, 2006. 370p.

CH00, C. W. A organização do conhecimento: como as organizações usam a informação para criar significado, construir conhecimento e tomar decisões. São Paulo: Editora SENAC, 2003. 425p.

COLOQUIO INTERNACIONAL DE CIENCIAS DE LA DOCUMENTACIÓN y VI Congreso del Capítulo Español de ISKO, 4. Tendencias de Investigación en Organización del Conocimiento. Trends in knowledge organization research. Salamanca, España: Ediciones Universidad de Salamanca, 2003.

CORREA, F. A gestão do conhecimento holística: delineamento teórico conceitual. Perspectivas em Ciência da Informação, Belo Horizonte, v.24, n.1, p.122-146, mar. 2019. Disponível em: http:// portaldeperiodicos.eci.ufmg.br/index.php/pci/article/view/3542/2255 Acesso em: 10 set. 2020.

DAFT, R. L.; WEICK, K. E. Toward a model of organizations as interpretation systems. The Academy of Management Review, v.9, n.2, p.284-295, 1984. Disponível em: https://www.jstor.org/stable/258441 Acesso em: 10 set. 2020.

DAHLBERG, I. Current trends in knowledge organization. In: GARCIA MARCO, F. J. (Org.). Organización del conocimiento en sistemas de información y documentación. Zaragoza: UNIZAR, 1995. v.1; p.7-26.

DALKIR, K. Knowledge management in theory and practice. 2.ed. Cambridge: Massachusetts Institute of Technology, 2011. 504p.

DAVENPORT, T. H.; MARCHAND, D. A.; DICKSON, T. Dominando a gestão da informação. Porto Alegre: Bookman, 2004. 407p.

DAVENPORT, T. H.; PRUSAK, L. Conhecimento empresarial: como as organizações gerenciam o seu capital intelectual. 5.ed. Rio de Janeiro: Campus, 1998. 237p.

DAVENPORT, T. H.; PRUSAK, L. Conhecimento empresarial. Rio de Janeiro: Campus, 1999. 237p.

DAVENPORT, T. H.; PRUSAK, L. Conhecimento empresarial: como as organizações gerenciam o seu capital intelectual. 12.ed. Rio de Janeiro: Elsevier, 2003. 237p.

DAVENPORT, T. H.; PRUSAK, L. Ecologia da informação: por que só a tecnologia não basta para 0 sucesso na era da informação. São Paulo: Futura, 1998. 316p.

DERVIN, B.; FOREMAN-WERNET, L.; LAUTERBACH, E. (Eds.). Sense-making methodology reader: Selected writings of Brenda Dervin. Cresskill: Hampton Press, 2003. 400p.

DIEPSTRATEN, J. Knowledge in action. Dordrecht: Triam, 1996. 
DOYLE, C. S. Information Literacy in an Information Society: A concept for the information age. New York: Information Resources, 1994. 82p. Disponível em: https://files.eric.ed.gov/fulltext/ED372763. pdf Acesso em: 10 set. 2020.

DRUCKER, P. Sociedade pós-capitalista. São Paulo: Pioneira, 1999. 299p.

DUARTE, E. N.; MORENO, D. H. da S.; MOTA, D. A. R.; SILVA, H. C. A. da; SILVA, J. M. 0; FERREIRA, T. E. de L. R. As pessoas e a tecnologia da informação na gestão do conhecimento: o ENANCIB como "contexto capacitante". Brazilian Journal of Information Science: Research Trends, Marília (SP), v.3, n.2, out. 2010. Disponível em: http://www2.marilia.unesp.br/revistas/index.php/bjis/article/ view/348/385 Acesso em: 10 set. 2020.

DUTRA, J. S. Competências: conceitos e instrumentos para a gestão de pessoas na empresa moderna. São Paulo: Atlas, 2004. 206p.

FIRESTONE, J. M. The corporate information factory or the corporate knowledge factory? DKMS Brief, n.1, p.1-6, 1999. Disponível em: http://www.dkms.com/CIFCKF.html Acesso em: 10 set. 2020.

FISCHER, A. L. 0 conceituo de modelo de gestão de pessoas: modismo e realidade em gestão de recursos humanos nas empresas brasileiras. In: DUTRA, J. S. (Org.). Gestão por competências: um modelo avançado para o gerenciamento de pessoas. 7.ed. São Paulo: Gente, 2001. 118p; p.9-23.

FTEIMI, N. Analyzing the literature on knowledge management frameworks: Towards a normative knowledge management classification schema. In: EUROPEAN CONFERENCE ON INFORMATION SYSTEMS, 23., 2015. Proceedings... Münster, 2015. 17p.

GRAY, P. H.; MEISTER, D. B. Introduction: Fragmentation and integration in knowledge management research. Information Technology \& People, v.16, n.3, p.259-265, 2003. Disponível em: https://doi. org/10.1108/09593840310489377 Acesso em: 10 set. 2020.

GURTEEN, D. Knowledge, creativity and innovation. Journal of Knowledge Management, London, v.2, n.1, p.5-13, 1998. Disponível em: https://doi.org/10.1108/13673279810800744 Acesso em: 10 set. 2020.

HARRIS, K. et al. The Impact of knowledge management on enterprise architecture. Stamford (CT): Gartner Group, 1999.

HARRIS, R. G. The knowledge-based economy: Intellectual origins and new economic perspectives. International Journal of Management Reviews, Oxford, v.3, n.1, p.21-40, Mar. 2001. Disponível em: https://doi.org/10.1111/1468-2370.00052 Acesso em: 10 set. 2020.

HEGAZY, F. M.; GHORAB, K. E. The influence of knowledge management on organizational business processes' and employees' benefits. International Journal of Business and Social Science, v.5, n.1, p.148-172, Jan. 2014. Disponível em: http://www.ijbssnet.com/journals/Vol_5_No_1_ January_2014/18.pdf Acesso em: 10 set. 2020.

HEISIG, P. Harmonisation of knowledge management: comparing $160 \mathrm{KM}$ frameworks around the globe. Journal of Knowledge Management, v.13, n.4, p.4-31, 2009. Disponível em: https://doi. org/10.1108/13673270910971798 Acesso em: 10 set. 2020. 
HIBBARD, J. Knowing what we know. Information Week Online, San Francisco (CA), 20 out. 1997.

HILDRETH, P. M.; KIMBLE, C. The duality of knowledge. Information Research, v.8, n.1, Oct. 2002. Disponível em: http://informationr.net/ir/8-1/paper142.html Acesso em: 10 set. 2020.

HIRSCH, P. M.; LEVIN, D. Z. Umbrella advocates versus validity police: A life-cycle model.

Organization Science, v.10, n.2, p.199-212, Mar./Apr. 1999. Disponível em: https://doi.org/10.1287/ orsc.10.2.199 Acesso em: 10 set. 2020.

HOFFMANN, W. A. M. Gestão do conhecimento e da informação em organizações baseados em inteligência competitiva. Ciência da Informação, Brasília, v.45, n.3, p.31-43, set./dez. 2016. Disponível em: http://revista.ibict.br/ciinf/article/view/4045/3564 Acesso em: 10 set. 2020.

HOLSAPPLE, C. W.; JOSHI, K. D. Description and analysis of existing knowledge management frameworks. In: ANNUAL HAWAII INTERNATIONAL CONFERENCE ON SYSTEMS SCIENCES, 32., 1999. Proceedings... Washington: IEEE Computer Society, 1999. 15p.

HOULTSHOUSE, D. Ten knowledge domains: Model of a knowledge-driven company? Knowledge and Process Management, v.6, n.1, p.3-8, Mar. 1999. Disponível em: https://doi.org/10.1002/(SICI)10991441(199903)6:1<3::AID-KPM45>3.0.C0;2-N Acesso em: 10 set. 2020.

INZAWA, F. K. 0 papel da cultura organizacional e da aprendizagem para o sucesso da gestão do conhecimento. Perspectivas em Ciência da Informação, Belo Horizonte, v.14, n.3, p.206-220, set./ dez. 2009. Disponível em: https://www.scielo.br/pdf/pci/v14n3/13.pdf Acesso em: 10 set. 2020.

JANNUZZI, C. S. C.; FALSARELLA, 0. M.; SUGAHARA, C. R. Gestão do conhecimento: um estudo de modelos e sua relação com a inovação nas organizações. Perspectivas em Ciência da Informação, Belo Horizonte, v.21, n.1, p.97-118, jn./mar. 2016. Disponível em: http://portaldeperiodicos.eci.ufmg. br/index.php/pci/article/view/2462/1715 Acesso em: 10 set. 2020.

KAKABADSE, N. K.; KAKABADSE, A.; KOUZMIN, A. Reviewing the knowledge management literature: Towards a taxonomy. Journal of Knowledge Management, v.7, n.4, p.75-91, 2003. Disponível em: https://doi.org/10.1108/13673270310492967 Acesso em: 10 set. 2020.

KIRN, S. Organizational intelligence and distributed artificial intelligence. In: O'HARE, G. M. P.; JENNINGS, N. R. (Eds.). Foundations of distributed artificial intelligence. New York: Wiley Interscience, 1996. 592p.; 505-526p. (Sixth Generation Computer Technology Series)

KOLB, D. A. A gestão e o processo de aprendizagem. In: STARKEY, K. (Ed.). Como as organizações aprendem: relatos do sucesso das grandes empresas. São Paulo: Futura, 1997. 488p.

KUHN, T. S. Estrutura das revoluções científicas. São Paulo: Perspectiva, 1975. 262p.

LASTRES, H. M. M., ALBAGLI, S. (Orgs.). Informação e globalização na era do conhecimento. Rio de Janeiro: Campus, 1999. 318p.

LAVE, J.; WENGER, E. Situated learning: Legitimate peripheral participation. Cambridge: Cambridge University Press, 1987. 138p. 
LE COADIC, Y. F. A Ciência da Informação. Brasília: Briquet de Lemos. 1996. 119p.

LEE, C. F.; TSAI, S. D-H.; AMJADI, M. The adaptive approach: Reflections on knowledge management models. Journal of Management Inquiry, v.21, n.1, p.30-41, Jan. 2012. Disponível em: https://doi. org/10.1177/1056492611411483 Acesso em: 10 set. 2020.

LEE, J-H.; KIM, Y-G. A stage model of organizational knowledge management: A latent content analysis. Expert Systems with Applications, Oxford, v.20, n.4, p.299-311, May 2001. Disponível em: 10.1016/S0957-4174(01)00015-X Acesso em: 10 set. 2020.

LEHANEY, B. et al. Beyond knowledge management. Hershey (PA): Idea Group, 2004. 276p.

LEITE, F. C. Lima. Comunicação científica e gestão do conhecimento: enlaces conceituais para a fundamentação da gestão do conhecimento científico no contexto de universidades.

Transinformação, Campinas (SP), v.19, n.2, p.139-151, maio/ago. 2007. Disponível em: https://www. scielo.br/pdf/tinf/v19n2/05.pdf Acesso em: 10 set. 2020.

LEITE, F. C. L.; COSTA, S. M. S. Gestão do conhecimento científico: proposta de um modelo conceitual com base em processos de comunicação científica. Ciência da Informação, Brasília, v.36, n.1, p.92-107, jan./abr. 2007. Disponível em: http://revista.ibict.br/ciinf/article/view/1189/1359 Acesso em: 10 set. 2020.

LENOX, M. F.; WALKER, M. L. Information literacy in the educational process. The Educational Forum, Indianapolis, v.57, n.2, p.312-324, Spring 1993. Disponível em: https://doi. org/10.1080/00131729309335431 Acesso em: 10 set. 2020.

LÉVY, P. A inteligência coletiva: por uma antropologia do ciberespaço. 3.ed. São Paulo: Loyola, 2000a. 212p.

LÉVY, P. As tecnologias de inteligência: o futuro do pensamento na era da informática. Rio de Janeiro: Editora 34, 2000b. 208p.

LIEBOWITZ, J. Strategic intelligence: business intelligence, competitive intelligence, and knowledge management. Boca Raton (FL): Auerbach, 2006. 242p.

LONGO, R. M. J. et al. Gestão do conhecimento: a mudança de paradigmas no século XXI. São Paulo: Editora SENAC, 2014. 268p.

MACHADO NETO, N. R. Gestão de conhecimento como diferencial competitivo. SEMINÁRIO GERENCIAMENTO DA INFORMAÇÃO NO SETOR PÚBLICO E PRIVADO, 4., 1998, Brasília. Anais... Brasília: Linker, 1998.

MALHOTRA, Y. Knowledge management \& new organization forms: A framework for business model. Information Resources Management Journal, v.13, n.1, p.5-14, Jan./Mar. 2000. Disponível em: http://www.brint.org/KMNewOrg.pdf Acesso em: 10 set. 2020.

MARSICK, V. J.; WATKINS, K. E. Facilitating learning organizations: Making learning count. Aldershot: Gower, 1999. 222p. 
MARTENSSON, M. A critical review of knowledge management as a management tool. Journal of Knowledge Management, v.4, n.3, p.204-216, 2000. Disponível em: https://doi. org/10.1108/13673270010350002 Acesso em: 10 set. 2020.

MATOS, G. A. Storytelling: líderes narradores de histórias. Rio de Janeiro: Qualitymark, 2010. 176p.

MATURANA, H. R; VARELA, F. J. A árvore do conhecimento: as bases da compreensão humana. São Paulo: Palas Athena, 2001. 283p.

MCGARRY, K. 0 contexto dinâmico da informação. Brasília: Briquet de Lemos, 1999. 206p.

METAXIOTIS, K.; ERGAZAKIS, K.; PSARRAS, J. Exploring the world of knowledge management: Agreements and disagreements in the academic/practitioner community. Journal of Knowledge Management, v.9, p.2, p.6-18, 2005. Disponível em: https://doi.org/10.1108/13673270510590182 Acesso em: 10 set. 2020.

MIRANDA, R. C. da R. 0 uso da informação na formulação de ações estratégicas pelas empresas. Ciência da Informação, Brasília, v.28, n.3, p.284-290, set./dez. 1999. Disponível em: https://www. scielo.br/pdf/ci/v28n3/v28n3a6.pdf Acesso em: 10 set. 2020.

MIRANDA, S. V. Identificando competências informacionais. Ciência da Informação, Brasília, v.33, n.2, p.112-122, maio/ago. 2004. Disponível em: http://revista.ibict.br/ciinf/article/view/1053/1132 Acesso em: 10 set. 2020.

MISHRA, B.; BHASKAR, A. U. Knowledge management process in two learning organisations. Journal of Knowledge Management, v.15, n.2, p.344-359, 2011. Disponível em: https://doi. org/10.1108/13673271111119736 Acesso em: 10 set. 2020.

MORESI, E. A. D. Inteligência organizacional: um referencial integrado. Ciência da Informação, Brasília, v.30, n.2, p.35-46, maio/ago. 2001. Disponível em: http://revista.ibict.br/ciinf/article/ view/923/960 Acesso em: 10 set. 2020.

MORIN, E. Introdução ao pensamento complexo. Porto Alegre: Sulina, 2005. 120p.

MORIN, E. 0 método 3: o conhecimento do conhecimento. Porto Alegre: Sulina, 1999. 288p.

MORIN, E. Os sete saberes necessários à educação do futuro. 6.ed. São Paulo: Cortez; Brasília: UNESCO, 2002. 118p.

NEMATI, M. Study the of organizational socialization, psychological capital, knowledge sharing and trust on employees' tendency to organizational innovation. Applied Mathematics in Engineering, Management and Technology, v.3, n.1, p.733-742, 2015. Disponível em: http://ashm-journal.com/ test/vol3-1/85.pdf Acesso em: 10 set. 2020.

NONAKA, I.; KONNO, N. The concept of "ba": Building a foundation for knowledge creation.

California Management Review, Berkeley, v.40, n.3, p.40-54, Apr. 1998. Disponível em: https://doi. org/10.2307/41165942 Acesso em: 10 set. 2020. 
NONAKA, I.; TAKEUCHI, H. The knowledge creating company: How Japanese companies create the dynamics of innovation. New York: Oxford University Press, 1995.

NONAKA, I.; TAKEUCHI, H. Criação do conhecimento na empresa: como as empresas japonesas geram a dinâmica da inovação. Rio de Janeiro: Campus, 1997. 358p.

NONAKA, I.; TAKEUCHI, H. Criação de conhecimento na empresa: como as empresas japonesas geram a dinâmica da inovação. Rio de Janeiro: Bookman, 2008. 320p.

NONAKA, I.; TOYAMA, R. The knowledge-creating theory revisited: Knowledge creation as a synthesizing process. Knowledge Management Research \& Practice, v.1, p.2-10, Jul. 2003. Disponível em: https://doi.org/10.1057/palgrave.kmrp.8500001 Acesso em: 10 set. 2020.

NURCAN, S.; BARRIOS, J. Enterprise knowledge and information system modelling in an evolving environment. In: INTERNATIONAL WORKSHOP ON ENGINEERING METHODS TO SUPPORT INFORMATION SYSTEM EVOLUTION (EMSISE'03), 1., 2-5 Sep., Geneva, 2003. Proceedings... Geneva, 2003. p.1-15. Disponível em: http://crinfo.univ-paris1.fr/users/nurcan/pdf/emsise2003.pdf Acesso em: 10 set. 2020.

OECD. Survey on knowledge management: practices for ministries / departments / agencies of central government in OECD member countries. Paris, 2002.

OYE, N. D.; MAZLEENA, S.; NOORMINSHAH, A. Knowledge sharing in workplace: Motivadoras and demotivators. International Journal of Managing Information Technology (IJMIT), v.3, n.4, p.71-84, Nov. 2011. Disponível em: http://airccse.org/journal/ijmit/papers/3411ijmit06.pdf Acesso em: 10 set. 2020.

PÁEZ-URDANETA, I. Gestión de la inteligencia, aprendizaje tecnológico y modernización del trabajo informacional. Retos y oportunidades. Caracas: Instituto de Estudios del Conocimiento de la Universidad Simon Bolivar; Consejo Nacional de Investigaciones Científicas y Tecnológicas, 1992. $253 p$.

PAIVA, S. B.; ARAGÃO, P. 0. R. de; PEREIRA, S. L. Gestão do conhecimento em uma organização baseada em conhecimento: uma abordagem qualitativa. Produto \& Produção, v.8, n.2, p.37-56, jun. 2005. Disponível em: http://www.seer.ufrgs.br/index.php/ProdutoProducao/article/viewFile/3212/1766 Acesso em: 10 set. 2020.

PEMBERTON, J. D.; STONEHOUSE, G. H.; YARROW, D. J. Benchmarking and the role of organizational learning in developing competitive advantage. Knowledge and Process Management, v.8, n.2, p.123135, Apr./Jun. 2001. Disponível em: https://doi.org/10.1002/kpm.110 Acesso em: 10 set. 2020.

PELUFFO-ARGÓN, M. B.; CATALÁN-CONTRERAS, E. Introducción a la gestión del conocimiento y su aplicación al sector público. Santiago de Chile: ILPES, 2002. 92p. (Serie Manuales, 22). Disponível em: https://tecnoadministracionpub.files.wordpress.com/2012/08/u5-comp-peluffo-contreras-intro. pdf Acesso em: 10 set. 2020.

PEREIRA, H. J. Bases conceituais de um modelo de gestão para organizações baseadas no conhecimento. In: SIMPÓSIO DE GESTÃO DA INOVAÇÃO TECNOLÓGICA, 22., Salvador, novembro de 
2002. Anais... Salvador NPGCT/USP, 2002. Disponível em: http://www.nota10.com.br/notas/bases. pdf Acesso em: 10 set. 2020.

PETRASH, G. Managing knowledge assets for value. In: Knowledge-Based Leadership Conference. Boston: Linkage, 1996.

POLANYI, M. The tacit dimension. London: Routledge and Kegan Paul, 1966. 108p.

POLANYI, M. The tacit dimension. New York: Anchor Books, 1967. 119p.

POWELL, T. W. The high tech marketing machine: Applying the power of computers to out-smart the competition. Chicago (IL): Probus Professional, 1993. 232p.

PROBST, G.; RAUB, S.; ROMHARDT, K. Gestão do conhecimento: os elementos construtivos do sucesso. Porto Alegre: Bookman, 2002. 288p.

PRUSAK, L. Where did knowledge management came from? IBM Systems Journal, Riverton (NJ), v.40, n.4, p.1002-1007, Oct. 2001. Disponível em: https://doi.org/10.1147/sj.404.01002 Acesso em: 10 set. 2020.

QUINN, J. B.; ANDERSON, P.; FINKELSTEIN, S. Gerenciando o intelecto profissional: obtendo 0 máximo dos melhores. In: ULRICH, D. (Org.). Recursos humanos estratégicos: novas perspectivas para os profissionais de RH. São Paulo: Futura, 2000. p.275-291.

RIBEIRO, E. M.; CHASSAGNES-IZQUIERDO, 0. E. Gestão do conhecimento e governança no setor público. Salvador: UFBA, 2017. 104p. (Coleção Gestão de Pessoas com Ênfase em Gestão de Competências). Disponível em: http://educapes.capes.gov.br/handle/capes/174973 Acesso em: 10 set. 2020.

RODRIGUES, B. A hora da gestão do conhecimento. Web Insider, 26 out. 2001. Disponível em: https://web.archive.org/web/20031013225753/http://webinsider.uol.com.br:80/vernoticia. php?id=1047 Acesso em: 10 set. 2020.

ROWLEY, J. What is knowledge management? Library Management, Bradford, v.20, n.8, p.416-420, 1999. Disponível em: https://doi.org/10.1108/01435129910291175 Acesso em: 10 set. 2020.

RUBENSTEIN-MONTANO, B. et al. A systems thinking framework for knowledge management. Decision Support Systems, v.31, n.1, p.5-16, 2001. Disponível em: https://coek.info/pdf-a-systemsthinking-framework-for-knowledge-management-.html Acesso em: 10 set. 2020.

RUMELHART, D. E. Schemata: the building blocks of cognition. In: SPIR0, R. J. et al. (Eds.). Theoretical issues in reading comprehension. Hillsdale (NJ): Lawrence Erlbaum, 1980.

SACKMANN, S. A. Culture and subcultures: An analysis of organizational knowledge. Administrative Science Quaterly, v.37, n.1, p.140-161, 1992. Disponível em: https://www.jstor.org/stable/2393536 Acesso em: 10 set. 2020.

SAMPAIO, T. S.; MENEZES, A. M. F. Gestão do conhecimento científico como síntese interdisciplinar: interfaces teórico-conceituais entre a gestão do conhecimento, a comunicação científica e a 
comunicação organizacional. Ponto de Acesso, Salvador, v.13, n.3, p.167-183, dez. 2019. Disponível em: https://portalseer.ufba.br/index.php/revistaici/article/view/34899/20747 Acesso em: 10 set. 2020.

SANTOS, P. L. V. A. da C.; SANT'ANA, R. C. G. Transferência da informação: análise para valoração de unidades de conhecimento. DataGramaZero, Rio de Janeiro, n.2, v.3, abr. 2002. Disponível em: https://brapci.inf.br/index.php/res/v/5349 Acesso em: 10 set. 2020.

SCARBROUGH, H.; SWAN, J. Explaining the diffusion of knowledge management: the role of fashion. British Journal of Management, v.12, n.1, p.3-12, Mar. 2001. Disponível em: https://doi. org/10.1111/1467-8551.00182 Acesso em: 10 set. 2020.

SCHOLL, W. et al. The future of knowledge management: An international delphi study. Journal of Knowledge Management, v.8, n.2, p.19-35, 2004. Disponível em: https://www.psychologie.hu-berlin. de/de/prof/org/download/scholl_et_al_2004_delphi.pdf

SCHULTZE, U.; STABELL, C. Knowing what you don't know?: Discourses and contradictions in knowledge management research. Journal of Management Studies, v.41, n.4, p.549-573, May 2004. Disponível em: https://doi.org/10.1111/j.1467-6486.2004.00444.x Acesso em: 10 set. 2020.

SEATON-MOORE, C. E.; BRESÓ-BOLINCHES, S. El desarrollo de un sistema de gestión del conocimiento para los institutos tecnológicos. Revista Espacios, Caracas, v.22, n.3, 2001. Disponível em: https://www.revistaespacios.com/a01v22n03/01220321.html Acesso em: 10 set. 2020.

SENGE, P. M. The fifth discipline: The art and practice of the learning organization. New York: Broadway Business, 2006. 445p.

SHANNON, C. E.; WEAVER, W. The Mathematical Theory of Communication. Urbana (IL): University of Illinois Press, 1963. 125p.

SOUZA, E. D. de; DIAS, E. J. W.; NASSIF, M. E. A gestão da informação e do conhecimento na ciência da informação: perspectivas teóricas e práticas organizacionais. Informação \& Sociedade: Estudos, João Pessoa, v.21, n.1, p.55-70, jan./abr. 2011. Disponível em: https://periodicos.ufpb.br/ojs2/index. php/ies/article/view/4039/5598 Acesso em: 10 set. 2020.

SOUTO, P. C. N. Knowledge management: Uncovering risky gaps underlying the criticisms and moving to another perspective. Ciência da Informação, Brasília, v.36, n.2, p.64-73, maio/ago. 2007. Disponível em: https://brapci.inf.br/index.php/res/v/22320 Acesso em: 10 set. 2020.

SPEK, R. van der; SPIJKERVET, A. Knowledge management: Handling knowledge with intelligence. Handboek Effectief Opleiden, v.9, n.13, p.1-32, 1995.

SPENDER, J. C. Organizational knowledge, learning and memory: Three concepts in search of a theory. Journal of Organizational Change Management, v.9, n.1, p.63-78, Feb. 1996. Disponível em: https://doi.org/10.1108/09534819610156813 Acesso em: 10 set. 2020.

SPRENGER, C. C. Four competences of the learning organization. Gravenhage: Delwel, 1995. 
STATA, R. Aprendizagem organizacional: a chave da inovação gerencial. In: STARKEY, K. (Ed.). Como as organizações aprendem: relatos do sucesso das grandes empresas. São Paulo: Futura, 1997. $488 p$.

STEWART, T. A. Capital intelectual: a nova vantagem competitiva nas empresas. Rio de Janeiro: Campus, 1998. 237p.

STEWART, T. A. A riqueza do conhecimento: o capital intelectual e a nova organização. Rio de Janeiro: Campus, 2002. 517p.

SULLIVAN, P. H. Value-driven intellectual capital: How to convert intangible corporate assets in market value. São Francisco: Wiley, 2000. 240p.

SVEIBY, K. E. A nova riqueza das organizações: gerenciando e avaliando patrimônios de conhecimento. Rio de Janeiro: Campus, 1998. 260p.

TAKEUCHI, H.; NONAKA, I. Gestão do conhecimento. Porto Alegre: Bookman, 2008. 320p.

TERRA, J. C. C. Gestão do conhecimento: o grande desafio empresarial. 5.ed. Rio de Janeiro: Elsevier, 2005. 315p.

TERRA, J. C. C. Gestão do conhecimento - o grande desafio empresarial: uma abordagem baseada no aprendizado e na criatividade. São Paulo: Negócio, 2000. 286p.

TERRA, J. C. Storytelling como ferramenta de gestão. São Paulo: Terra Fórum Consultores, s.d. 6p. Disponível em: https://pt.slideshare.net/jcterra/storytelling-como-ferramenta-de-gesto Acesso em: 10 set. 2020.

TIDD, J.; BESSANT, J. Gestão da inovação. 5.ed. Porto Alegre: Bookman, 2015. 648p.

TIWANA, A. The knowledge management toolkit: Practical techniques for building a knowledge management system. New Jersey: Prentice-Hall, 2000. 608p.

VALENTIM, M. L. P. A importância do compartilhamento de conhecimento em ambientes empresariais. In: CIANCONI, R. de B.; CORDEIRO, R. I. de N.; ALMEIDA, C. H. M. de (Orgs). Gestão do conhecimento, da informação e de documentos em contextos informacionais. Niterói: EDUFF, 2013. p.59-80 (Coleção Estudos da Informação, 3)

VALENTIM, M. L. P. Cultura organizacional e gestão do conhecimento. InfoHome, Londrina (PR), 2003. 2p. Disponível em: https://www.ofaj.com.br/colunas_conteudo.php?cod=70 Acesso em: 10 set. 2020.

VALENTIM, M. L. P. Gestão da informação e gestão do conhecimento em ambientes organizacionais: conceitos e compreensões. Tendências da Pesquisa Brasileira em Ciência da Informação, v.1, n.1, 2008. Disponível em: http://hdl.handle.net/20.500.11959/brapci/119521 Acesso em: 10 set. 2020.

VALENTIM, M. L. P. Inteligência competitiva em organizações: dado, informação e conhecimento. DataGramaZero, Rio de Janeiro, v.3, n.4, ago. 2002. Disponível em: http://hdl.handle. net/20.500.11959/brapci/3837 Acesso em: 10 set. 2020. 
VALENTIM, M. L. P. Processos de compartilhamento e socialização do conhecimento em ambientes empresariais. Ciência da Informação, Brasília, v.45, n.3, p.97-109, set./dez. 2016. Disponível em: http://revista.ibict.br/ciinf/article/view/4050/3570 Acesso em: 10 set. 2020.

VALENTIM, M. L. P.; GELINSKI, J. V. V. Gestão do conhecimento como parte do processo de inteligência competitiva organizacional. Informação \& Sociedade: Estudos, João Pessoa, v.15, n.2, 2005. Disponível em: https://periodicos.ufpb.br/ojs2/index.php/ies/issue/view/6 Acesso em: 10 set. 2020.

VALENTIM, M. L. P.; JORGE, C. F. B.; CERETTA-SORIA, M. G. Contribuição da competência em informação para os processos de gestão da informação e do conhecimento. Em Questão, Porto Alegre, v.20, n.2, p.207-231, jul./dez. 2014. Disponível em: https://seer.ufrgs.br/EmQuestao/article/ view/48642/32122 Acesso em: 10 set. 2020.

VAN ZOLINGEN, S.; STREUMER, J. N.; STOOKER, M. Problems in knowledge management: a case study of a knowledge-intensive company. International Journal of Training and Development, v.5, n.3, p.168-184, 2001. Disponível em: https://doi.org/10.1111/1468-2419.00130 Acesso em: 10 set. 2020.

VIGOTSKY, L. S. Pensamento e linguagem. 2.ed. São Paulo: Martins Fontes, 1998. 194p.

VON KROGH, G.; ICHIJO, K.; NONAKA, I. Facilitando a criação de conhecimento: reinventando a empresa com o poder da inovação contínua. Rio de Janeiro: Campus, 2001. 350p.

WEGGEMAN, M. Knowledge management. Schiedam: Scriptum, 1997.

WIIG, K. M. Knowledge management foundations: Thinking about thinking - how people and organizations represent, create and use knowledge. Arlington (TX): Schema, 1993. 471p.

WILSON, T. D. The nonsense of 'knowledge management'. Information Research, v.8, n.1, Oct. 2002. Disponível em: http://informationr.net/ir/8-1/paper144.html Acesso em: 10 set. 2020.

WILSON, T. D. A problemática da gestão do conhecimento. In: TARAPANOFF, K. (Org.). Inteligência, informação e conhecimento em corporações. Brasília: IBICT; UNESCO, 2006. p.37-55.

WURMAN, R. S. Ansiedade de informação: como transformar informação em compreensão. 5.ed. São Paulo: Cultura Editores, 1995. 380p.

ZACK, M. Management codified knowledge. Sloan Management Review, v.40, n.4, p.45-58, Jul., 1999. Disponível em: https://sloanreview.mit.edu/article/managing-codified-knowledge/ Acesso em: 10 set. 2020. 